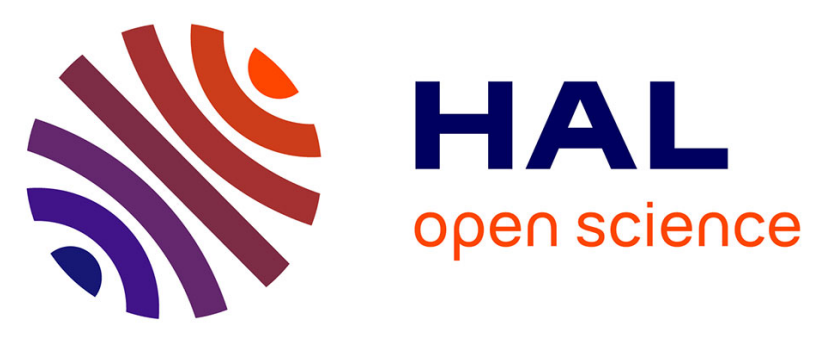

\title{
A scalable synthesis route for multiscale defect engineering in the sustainable thermoelectric quaternary sulfide Cu26V2Sn6S32
}

Gabin Guelou, Christophe Couder, Abdelhamid Bourhim, Oleg Lebedev, Nina Daneu, Florian Appert, Jean Juraszek, Pierric Lemoine, Lorraine Segreto, Emmanuel Guilmeau

\section{To cite this version:}

Gabin Guelou, Christophe Couder, Abdelhamid Bourhim, Oleg Lebedev, Nina Daneu, et al.. A scalable synthesis route for multiscale defect engineering in the sustainable thermoelectric quaternary sulfide Cu26V2Sn6S32. Acta Materialia, 2020, 195, pp.229-239. 10.1016/j.actamat.2020.05.039 . hal-02882105

\section{HAL Id: hal-02882105}

https://hal-normandie-univ.archives-ouvertes.fr/hal-02882105

Submitted on 9 Jul 2020

HAL is a multi-disciplinary open access archive for the deposit and dissemination of scientific research documents, whether they are published or not. The documents may come from teaching and research institutions in France or abroad, or from public or private research centers.
L'archive ouverte pluridisciplinaire HAL, est destinée au dépôt et à la diffusion de documents scientifiques de niveau recherche, publiés ou non, émanant des établissements d'enseignement et de recherche français ou étrangers, des laboratoires publics ou privés. 
Full paper

\section{A scalable synthesis route for multiscale defect engineering in the sustainable thermoelectric quaternary sulfide $\mathrm{Cu}_{26} \mathrm{~V}_{2} \mathrm{Sn}_{6} \mathrm{~S}_{32}$}

Gabin Guélou, ${ }^{\mathrm{a}}$ Christophe Couder, ${ }^{\mathrm{a}}$ Abdelhamid Bourhim, ${ }^{\mathrm{a}}$ Oleg I. Lebedev, ${ }^{\mathrm{a}}$ Nina Daneu, Florian Appert, ${ }^{\mathrm{c}}$ Jean Juraszek, ${ }^{\mathrm{c}}$ Pierric Lemoine, ${ }^{\mathrm{d}}$ Lorraine Segreto, ${ }^{\mathrm{e}}$ Emmanuel Guilmeau*,

a CRISMAT, CNRS, Normandie Univ, ENSICAEN, UNICAEN, 14000 Caen, France

b Department for Advanced Materials, Jožef Stefan Institute, Jamova cesta 39, 1000 Ljubljana, Slovenia

c GPM, CNRS, Univ Rouen, INSA Rouen, UNIROUEN, 76000 Rouen, France

d ISCR - UMR 6226, CNRS, Univ Rennes, F-35000 Rennes, France

e Tribotecc GmbH, Industriestrasse 23, A-9601 Arnoldstein, Austria

* corresponding author: emmanuel.guilmeau@ensicaen.fr

Graphical Abstract
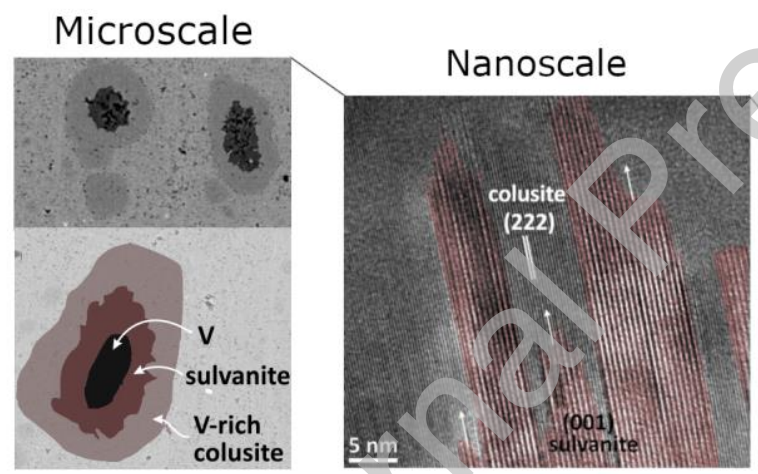

\section{Defect engineering}

Structural disorder

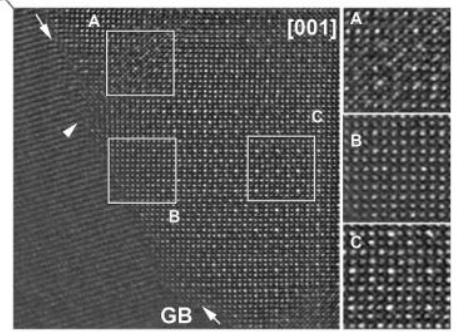

\section{Abstract}

In recent years, thermoelectric materials inspired from the natural mineral colusite have emerged as a new class of environmentally-friendly copper-based sulfides composed of abundant elements. Herein, high performance bulk colusite $\mathrm{Cu}_{26} \mathrm{~V}_{2} \mathrm{Sn}_{6} \mathrm{~S}_{32}$ materials were synthesized using mechanical alloying and spark plasma sintering of low-cost industrial-grade metal sulfides. This new synthesis route has led to the formation of various types of nano-tomicroscale defects, from local Sn-site structural disorder to nano-inclusions and vanadiumrich core-shell microstructures. These multiscale defects have a strong impact over phonon 
scattering, making it possible to reach ultra-low lattice thermal conductivity. Simultaneously, the electrical transport properties are impacted through variations in charge carrier concentration and effective mass, leading to a synergistical improvement of both electrical and thermal properties. The resulting power factor, over $1 \mathrm{~mW} \mathrm{~m}^{-1} \mathrm{~K}^{-2}$ above $623 \mathrm{~K}$ with an average value of $0.86 \mathrm{~mW} \mathrm{~m}^{-1} \mathrm{~K}^{-2}$ over the temperature range $300 \leq T / \mathrm{K} \leq 650 \mathrm{~K}$, is the highest reported for a germanium-free colusite to date. Our optimization strategy based on defect engineering in bulk materials is an exciting prospect for new low-cost thermoelectric systems.

Keywords: thermoelectric; defect engineering; sulfide; colusite; mechanical alloying 


\section{Introduction}

In recent years, there has been a growing interest in any sources of renewable energy that could curtail our reliance on fossil fuels and reduce our emission of greenhouse gases. Among these, thermoelectricity (TE) is one of the potential technologies that could be used in order to mitigate climate change and the dramatic environmental ramifications associated with it. However, the cost-efficiency relative to the conversion of waste heat into useful electrical current remains low for TE devices even with the current best performing bulk materials.[13] In order to be environmentally significant, TE devices must be commercially viable on a much larger scale than for the current niche applications. Naturally, the materials that constitute TE devices must meet new scale-up-friendly criteria such as availability and low toxicity of the precursors, synthesis route, mechanical properties, stability, etc. In addition to these requirements, new strategies to improve TE performances must be applicable on a large scale production.

Current performing materials are not only prohibitively expensive but also heavy, toxic and often scarce, such as derivatives of bismuth and lead tellurides.[1,4-8] This has fueled the certain level of skepticism over thermoelectricity as a promising source of renewable energy.[3] Fortunately, a second wind was given to the research on earth-abundant sulfides following the reports of outstanding properties in a variety of ternary and quaternary $n$ - and $p$ type copper sulfides, paving a new way for cheap, light and non-toxic thermoelectric materials. Members of this particularly promising group of materials, often derivatives of natural minerals, include but are not limited to: bornite $\mathrm{Cu}_{5} \mathrm{FeS}_{4},[9-11]$ germanite derivative $\mathrm{Cu}_{22} \mathrm{Fe}_{8} \mathrm{Ge}_{4} \mathrm{~S}_{32},[12,13]$ stannoidite $\mathrm{Cu}_{8.5} \mathrm{Fe}_{2.5} \mathrm{Sn}_{2} \mathrm{~S}_{12},[14]$ colusites $\mathrm{Cu}_{26} T_{2} M_{6} \mathrm{~S}_{32}(T=\mathrm{V}, \mathrm{Nb}$, Ta, Cr, Mo, W; $M=\mathrm{Sn}, \mathrm{Ge}),[15-24] \quad \mathrm{Cu}_{2} \mathrm{SnS}_{3},[25]$ kesterite $\mathrm{Cu}_{2} \mathrm{ZnSnS}_{4},[26,27]$ $\mathrm{Cu}_{4} \mathrm{Sn}_{7} \mathrm{~S}_{16},[28] \mathrm{CuFeS}_{2}$ [29] and tetrahedrites $\mathrm{Cu}_{12-x} T_{x} \mathrm{Sb}_{4} \mathrm{~S}_{13}(T=\mathrm{Mn}, \mathrm{Fe}, \mathrm{Ni}, \mathrm{Zn})$.[30-36] Some of these materials exhibit bulk performances close to those of the commercially 
available bismuth telluride derivatives with a figure of merit $\left(Z T=S^{2} T / \rho \kappa\right.$ where $T$ is the absolute temperature, $S$ the Seebeck coefficient, $\rho$ the electrical resistivity, and $\kappa$ the thermal conductivity) around unity at intermediate temperatures. Among those, the V-Sn colusite, $\mathrm{Cu}_{26} \mathrm{~V}_{2} \mathrm{Sn}_{6} \mathrm{~S}_{32}$, is an exceptionally attractive candidate with an optimized $Z T$ of 0.9 at $700 \mathrm{~K}$ from earth-abundant light elements.

In order to develop a cost-effective thermoelectric material that could bring thermoelectricity closer to a wide-spread application, we have initiated the scale-up production of V-Sn colusite in an attempt to address some industrial concerns. Of those, cost and availability of the precursors and the synthetic route are of paramount importance, as well as the electrical and thermal performances and their reproducibility. We demonstrate that pure V-Sn colusite can be produced using cheap industrial-grade metal sulfides. These raw materials are readily available, easy to handle and do not require any particular care for storing. These precursors combined with elemental vanadium produced a colusite with similar performances than the high-purity counterpart despite a strikingly different behavior of the thermal conductivity. We also demonstrate the feasibility of a much larger scale production using ball milling in a nearindustrial scale (200 g per milling cycle). The choice of mechanical alloying in a planetary ball mill as a synthesis route is justified by the scalability and safety of the technique. In previous studies, the reproducibility and benefits of using such technique was already established for the synthesis of thermoelectric sulfides such as $\mathrm{TiS}_{2},[37] \mathrm{Bi}_{2} \mathrm{~S}_{3},[38]$ $\mathrm{Cu}_{4} \mathrm{Sn}_{7} \mathrm{~S}_{16}$, [28] $\mathrm{Cu}_{2} \mathrm{SnS}_{3}$, [39] $\mathrm{Cu}_{22} \mathrm{Fe}_{8} \mathrm{Ge}_{4} \mathrm{~S}_{32}$, [12], $\mathrm{Cu}_{6} \mathrm{Fe}_{2} \mathrm{SnS}_{8} / \mathrm{Cu}_{2} \mathrm{FeSnS}_{4}$ composite,[40] $\mathrm{Cu}_{8.5} \mathrm{Fe}_{2.5} \mathrm{Sn}_{2} \mathrm{~S}_{12},[14] \quad \mathrm{Cu}_{5} \mathrm{FeS}_{4},[10,41,42] \quad \mathrm{Cu}_{12-\mathrm{x}} T_{\mathrm{x}} \mathrm{Sb}_{4} \mathrm{~S}_{13} \quad(T=\mathrm{Ni}, \mathrm{Zn}) \quad[37,43] \quad$ and $\mathrm{Cu}_{26} T_{2} M_{6} \mathrm{~S}_{32}(T=\mathrm{V}, \mathrm{Cr}, \mathrm{Mo}, \mathrm{W} ; M=\mathrm{Sn}, \mathrm{Ge}),[17-20]$ Besides, our new synthesis route using industrial-grade precursors has led to the formation of various types of nano-to-microscale defects, from local Sn-site structural disorder to nano-inclusions and vanadium-rich core-shell 
microstructures. The results demonstrate that defect engineering is a simple and effective strategy to improve synergistically both electrical and thermal properties in bulk sulfides.

\section{Experimental Section}

\subsection{Synthesis}

Polycrystalline samples of $\mathrm{Cu}_{26} \mathrm{~V}_{2} \mathrm{Sn}_{6} \mathrm{~S}_{32}$ were synthesized by mechanical alloying using either all elemental precursors $\mathrm{Cu}$ (99.9\%, Alfa Aesar), V (99.9\%, Alfa Aesar), Sn (Merck $99.9 \%)$ and S (99.99\%, Alfa Aesar) or a combination of industrial-grade binary precursors SnS (99.5\%, Tribotecc, Frenostannid), CuS (99.5\%, Tribotecc, CB500) and V (99.9\%, Alfa Aesar). Small batches of products $(7 \mathrm{~g})$ were obtained from the high-energy ball-milling of the precursors in a $40 \mathrm{ml}$ tungsten carbide jar containing 14 balls of $10 \mathrm{~mm}$ in diameter under argon atmosphere in a Fritsch Pulverisette 7 Premium line planetary ball-mill operating at room temperature. For the large batches $(100 \mathrm{~g})$, the precursors were milled in a $250 \mathrm{ml}$ tungsten carbide jar containing 15 balls of $20 \mathrm{~mm}$ in diameter under argon atmosphere in a Fritsch Pulverisette 5 Premium line planetary ball-mill. The obtained powders were then loaded in $10 \mathrm{~mm}$ diameter graphite dies and densified by spark plasma sintering in a SPS-FCT HPD 25. The specific conditions for the milling and the densification are part of the study and are thus described and discussed in the main text.

While all milling were carried out in inert atmosphere (argon), storage and manipulation of the industrial precursors and the products of up-scaled mechanical alloying were done in air. No oxidation or deterioration of the samples was observed over the time-scale of the production. Once consolidated, all samples appear to be stable in air.

\subsection{Electrical and thermal properties measurements.}

The electrical resistivity $(\rho)$ and Seebeck coefficient $(S)$ were measured simultaneously from ingots cut from the obtained pellets in central and axial positions, from $300 \mathrm{~K}$ up to $700 \mathrm{~K}$ on 
heating and cooling using an ULVAC-ZEM3 instrument under partial helium pressure. A NETZSCH LFA-457 instrument was used for the measurement of the thermal diffusivity under argon flow. The thermal conductivity $(\kappa)$ was determined as the product of the geometrical density (confirmed by Archimedes' method), the thermal diffusivity, and the theoretical heat capacity using the Dulong-Petit approximation. The lattice contribution to the thermal conductivity $\left(\kappa_{L}\right)$ was determined by subtracting the estimated electronic component $\left(\kappa_{e}\right)$ from the measured total thermal conductivity $(\kappa)$. The electronic contribution $\left(\kappa_{e}\right)$ was obtained from the Wiedemann-Franz law, $\kappa_{e}=L \sigma T$, where the Lorenz number, $L$, was approximated from the Seebeck coefficient using the simplified expression $L=1.5+\exp (-$ $|\mathrm{S}|$ 116) from Kim et al.[44]

Simultaneous TG and DSC analyses were carried out on cold-pressed pre-SPS powders using a Netzsch DSC 404 F3 Pegasus with a $10 \mathrm{~K} \mathrm{~min}^{-1}$ heating rate.

The estimated measurement uncertainties are $6 \%$ for the Seebeck coefficient, $8 \%$ for the electrical resistivity, $11 \%$ for the thermal conductivity, and $16 \%$ for the final figure of merit, ZT.[45]

\subsection{X-ray powder diffraction}

Rapid acquisition of X-ray powder diffraction (XRPD) were carried out on reactive powders (before SPS) using two X'PERT Pro MPD PANalytical (Phillips) equipped with either Co $\left(K \alpha_{1}=1.7890 \AA\right.$ and $\left.K \alpha_{2}=1.7929 \AA\right)$ or $\mathrm{Cu}\left(K \alpha_{1}=1.5406 \AA\right.$ and $\left.K \alpha_{2}=1.5444 \AA\right)$ anticathodes, depending on immediate availability. The diffractometer with the Co source was fitted with an $\mathrm{X}^{\prime}$ Celerator detector and an iron filter to eliminate $K \beta$ cobalt radiation while the diffractometer with the $\mathrm{Cu}$ source was fitted with a PIXcel3D detector and a nickel filter to eliminate $K \beta$ copper radiation. Both diffractometers' geometry configuration was BraggBrentano and all XRPD data presented in this study are given in term of $\mathrm{Cu}$ wavelength for clarity (uniformed 20). High-resolution X-ray powder diffraction (XRPD) data were collected 
at room temperature using a Bruker D8 Advance Vario 1 two-circle diffractometer $(\theta-2 \theta$ Bragg-Brentano mode) using $\mathrm{Cu} K \alpha$ radiation $(\lambda=1.5406 \AA$ ) with a Ge (111) monochromator (Johansson type) and a Lynx Eye detector. The XRPD data analyses were performed by Rietveld refinement using the GSAS and ExpGUI software packages.[46,47] Background contribution to the XRPD patterns were estimated manually. Zero-point shift, peak shape parameters, asymmetry parameters, lattice parameters, fractional atomic coordinates and isotropic displacement parameters (i.e. Debye-Waller factors $B_{i s o}$ ) were refined.

\subsection{Mössbauer spectroscopy}

${ }^{119} \mathrm{Sn}$ Mössbauer spectra of the polycrystalline powders were measured at $300 \mathrm{~K}$ in transmission geometry. The source was ${ }^{119 \mathrm{~m}} \mathrm{Sn}$ in $\mathrm{CaSnO}_{3}$ matrix with an activity of $\sim 370$ $\mathrm{MBq}$, mounted in a velocity transducer operating in constant-acceleration mode. Velocity calibration was performed by collecting the ${ }^{57} \mathrm{Fe}$ Mössbauer spectrum of a $\alpha$-Fe foil at RT from a second ${ }^{57}$ Co source mounted at the other side of the spectrometer. Isomer shifts $(\delta)$ are given with respect to $\mathrm{SnO}_{2}$ at $300 \mathrm{~K}$. Least-squares fits of the Mössbauer spectra were performed using the histogram method assuming Lorentzian lines.

\subsection{Microscopy}

Scanning electron micrographs were acquired on fractured cross-sections of consolidated samples (Fig. 2) using a ZEISS Supra 55 field emission scanning electron microscope. The transmission electron microscope (TEM), including electron diffraction (ED), high resolution TEM (HRTEM), the energy dispersive X-ray spectroscopy (EDX) elemental mapping analysis together with high-angle annular dark field scanning TEM (HAADF-STEM) was performed using a JEM ARM200F cold FEG probe and image aberration corrected electron microscope operated at $200 \mathrm{kV}$ and equipped with a large solid angle CENTURIO EDX detector and Quantum GIF. TEM samples were prepared by dispersion of fine powders of the samples in ethanol and that was transferred to a $\mathrm{Cu}$ holey carbon grid (Fig. 4-6). 
SEM analyses of polished cross-sections (samples SPS873 and SPS1083) were performed on field-emission gun scanning electron microscope (FEG-SEM; JSM-7600F, Jeol Ltd., Tokyo, Japan) operated at 10-20 kV, equipped with energy dispersive X-ray spectrometer (EDS; INCA Oxford 350 EDS SDD, Oxfordshire, UK). EDS spectra were acquired at standard conditions of $20 \mathrm{kV}$ accelerating voltage and $15 \mathrm{~mm}$ working distance. Polished crosssections of the samples were prepared by grinding and polishing, finally with 3-micron diamond lapping film.

Samples for conventional TEM analyses of the samples SPS873 and SPS1083 (Fig. 3(d, e) and Fig. S9b) were prepared using to the conventional procedure using thinning, dimpling and ion-milling. The sintered compacts were inserted into a brass tube with 3-mm diameter for support and fixed with epoxy resin. The samples were thinned from both sides to around 100 microns and further dimpled to around 15-microns in the disc center. Electron-transparent regions were obtained by ion milling (Gatan PIPS 691, California, USA) using $3.8 \mathrm{kV}$ Ar+ ions at an incidence angle of $10^{\circ}$ until perforation. Prior to TEM analyses, the specimens were coated by a thin layer ( $2 \mathrm{~nm}$ ) of carbon (Gatan PECS 682, California, USA) to improve surface electron conductivity and avoid sample charging under electron beam.

\section{Results and discussions}

\subsection{Synthesis}

The preparation of the ordered and disordered V-Sn colusite, $\mathrm{Cu}_{26} \mathrm{~V}_{2} \mathrm{Sn}_{6} \mathrm{~S}_{32}$, using high-purity elemental precursors has been described in a previous study and will be used here as a reference.[18] The carefully weighted mixture of elemental powders was ball milled for a total of $12 \mathrm{~h}$ at $600 \mathrm{rpm}$ followed by SPS at $873 \mathrm{~K}$, producing high-purity, well-ordered $\mathrm{Cu}_{26} \mathrm{~V}_{2} \mathrm{Sn}_{6} \mathrm{~S}_{32}$ with no significant concentration of defects.[18] In order to promote the scaleup production of colusite, we must first demonstrate the feasibility of colusite synthesis using simple, low-cost, industrial precursors $\mathrm{CuS}$ and $\mathrm{SnS}$. While vanadium was used as elemental 
precursor, it represents less than $3 \%$ of the total weight of precursors and should not constitute an issue for industrial scale production. A stoichiometric mixture of industrial-grade $\mathrm{CuS}$ and $\mathrm{SnS}$ and elemental $\mathrm{V}$ was subjected to a milling for a total of $10 \mathrm{~h}$ (see experimental section for details) with a rotation speed of $400 \mathrm{rpm}$ in 30 min cycles with $30 \mathrm{~min}$ intervals for cool down and change of milling direction, producing two simultaneous batches of $100 \mathrm{~g}$ each. The rather low milling speed of $400 \mathrm{rpm}$ corresponds to the maximum speed allowed for WC balls $(\varnothing 20 \mathrm{~mm})$ to ensure the longevity of the equipment and to limit sample contamination by WC particles. In all cases, a fine homogeneous black powder was obtained without significant aggregation, eliminating the need for thinning agent like stearic acid. In order to optimize the production for maximum energy efficiency, and avoid unnecessary milling time, small amounts of sample were collected at regular intervals, in air, and analyzed using X-ray powder diffraction (XRPD) (Fig. S1).

After $4 \mathrm{~h}$ to $5 \mathrm{~h}$, both binary precursors have completely reacted, leaving only the signature broad peaks of a poorly crystalline, disordered, cubic colusite phase.[17] Traces of vanadium metal remain in the powder even after $10 \mathrm{~h}$ of milling; however, no improvement was made from $8 \mathrm{~h}$ to $10 \mathrm{~h}$ milling, suggesting that the rather mild milling conditions imposed by the scale-up apparatus are energetically insufficient to fully react all precursors. Nonetheless, the subsequent heat treatment imposed to the pre-reacted powders during SPS is enough to crystallize the colusite phase. This is in agreement with reported synthesis and consolidation of mechanically alloyed V-Sn colusite.[17,18] Indeed, after SPS at $873 \mathrm{~K}$ for 30 min (heating rate $50 \mathrm{~K} \mathrm{~min}^{-1}$, cooling rate $20 \mathrm{~K} \mathrm{~min}^{-1}, \mathrm{P}=64 \mathrm{MPa}$ ), both samples sintered from pre-reacted powders subjected to $8 \mathrm{~h}$ and $10 \mathrm{~h}$ milling gave similar properties, with good thermal stability. For shorter milling times ( $1 \mathrm{~h}$ to $4 \mathrm{~h}$ ), the obtained samples exhibit lower performance and significant alteration upon cycling, evidencing incomplete reaction after SPS (Fig. S2). This was confirmed by the presence of many impurity reflections in the XRPD patterns after SPS 
(Fig. S3). Therefore, a minimum of $8 \mathrm{~h}$ of milling at $400 \mathrm{rpm}$ is necessary to provide sufficiently pre-reacted powders in order to crystallize the colusite phase during SPS. Large batches $(2 \times 100 \mathrm{~g}$ per milling $)$ of industrial-grade powders were then used to investigate the impact of SPS and to compare the thermoelectric properties of such V-Sn colusite with the previously reported lab-scale colusite prepared from high-purity elements. The heating and cooling rates, pressure and sintering time for the remaining samples were kept identical with only the sintering temperature varying.
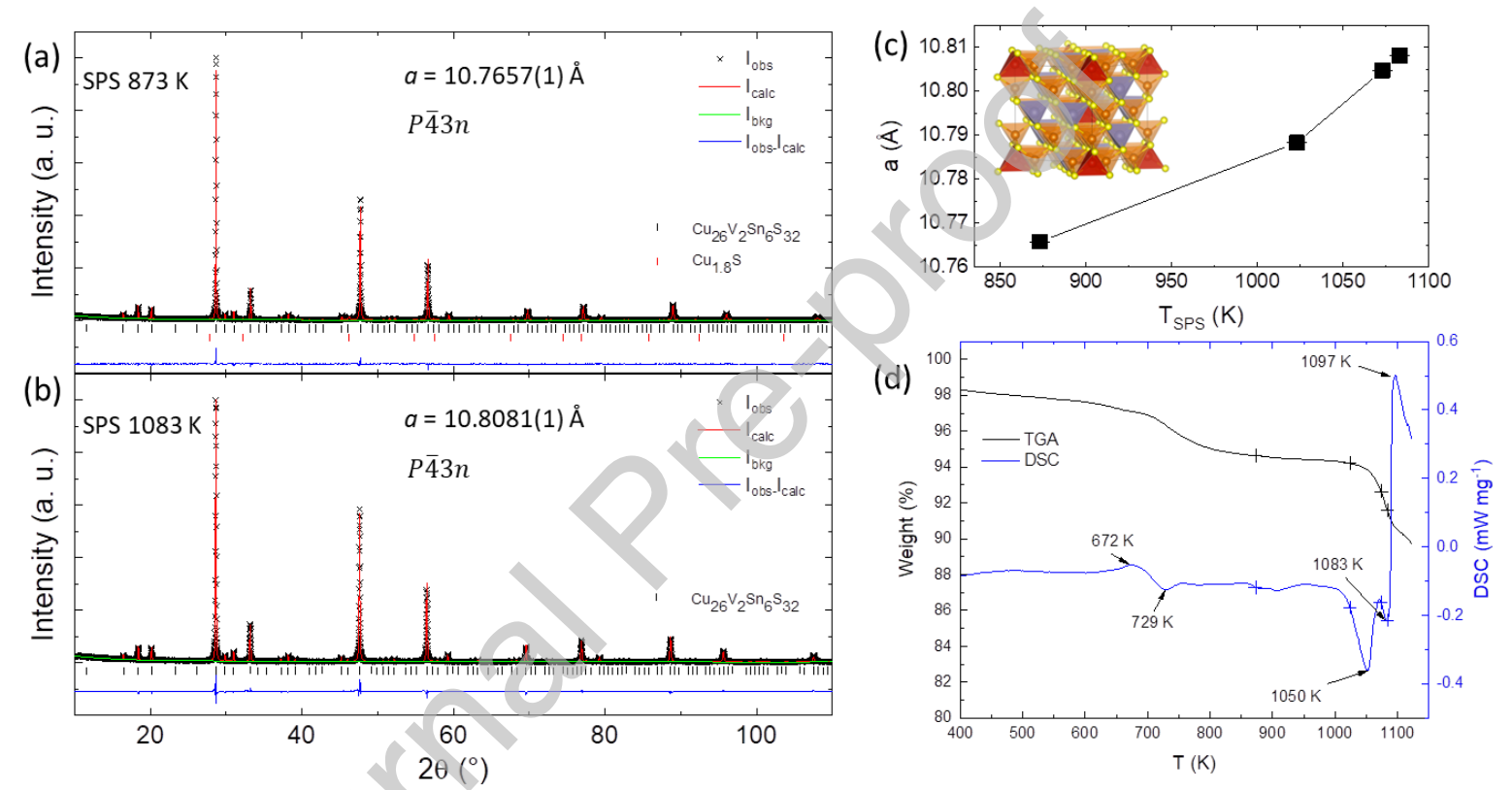

Figure 1. Rietveld refinement from XRPD room temperature data from a V-Sn sample sintered by SPS at (a) $873 \mathrm{~K}$ and (b) $1083 \mathrm{~K}$; (c) unit cell parameter, $a$, as a function of sintering temperature with the crystal structure representation of the colusite phase as inset; $\mathrm{V}$ in red, $\mathrm{Cu}$ in orange, $\mathrm{Sn}$ in grey and $\mathrm{S}$ in yellow; (d) TG/DSC measurements carried out on the mechanically alloyed powder prior to SPS treatment. The sintering temperatures of the four samples are marked by a cross.

\subsection{Structural and microstructural analysis}

After mechanical alloying of the industrial-grade precursors, phase-pure V-Sn colusite was crystallized during the SPS treatment and investigated through Rietveld refinement of high- 
resolution XRPD patterns (Fig. 1(a, b) and Fig. S4-S5). $\mathrm{Cu}_{26} \mathrm{~V}_{2} \mathrm{Sn}_{6} \mathrm{~S}_{32}$ crystallizes in the cubic $P \overline{4} 3 n$ space group with a unit cell parameter, $a$, ranging from $c a$. 10.7 to $c a$. $10.8 \AA$ depending on the concentration of defects.[18] The structure of V-Sn colusite (inset in Fig. 1c) is easily described as a $2 a \times 2 a \times 2 a$ supercell of a zinc blende-type "CuS" structure where 6 out of $32 \mathrm{Cu}$ atoms are replaced by $\mathrm{Sn}$, and $\mathrm{V}$ occupies an interstitial tetrahedral position ( $2 a$ site) at the origin of the supercell. The unit cell parameter $a$, determined from Rietveld refinement of the XRPD data for samples sintered at $873 \mathrm{~K}, 1023 \mathrm{~K}, 1073 \mathrm{~K}$ and $1083 \mathrm{~K}$, hereafter referred to as SPS873, SPS1023, SPS1073 and SPS1083 respectively, are

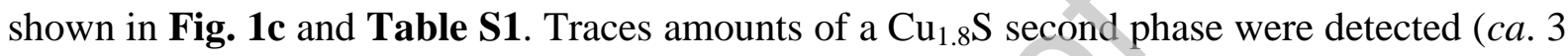
$\mathrm{wt} \%$ ) only for SPS873.

As expected, samples sintered at higher temperature exhibit a larger unit cell volume, consistent with the increased loss of sulfur through volatilization and the subsequent reorganization of structure with antisite defects and interstitial cations.[18,48] Note that the role of this interstitial atom, at the center of a mixed tetrahedral-octahedral complex is crucial to explain the outstanding electrical properties of colusite.[19,20,24] Indeed, a thorough investigation combining neutron diffraction, high-resolution XRPD and high-angle annular dark-field scanning transmission electron microscopy (HAADF-STEM) concluded that a high sintering temperature $(1023 \mathrm{~K})$ yielded colusite samples with a larger unit cell $(a \approx 10.83 \AA)$ and a higher concentration of defects compared to samples sintered at lower temperature (873 K). Such defects, ranging from 1D line Sn-vacancy and Sn-antisite defects to fully disordered regions, were responsible for the large improvement in the thermoelectric performance through an exceptional decrease in the lattice thermal conductivity.[18] The structural parameters obtained from Rietveld analysis (Table S1) shows two sets of atomic displacement parameters, $B_{\text {iso }}(\mathrm{V}$ and $\mathrm{S}(1)$ ), with unrealistic values that can be explained by the level of disorder in the structure. Indeed, atomic displacement parameters are often refined 
to non-sensible values to compensate for an inadequate structural model. In the present case, the level of disorder in both the cationic arrangement, caused by sulfur loss, and the microstructure, caused by the short crystallization time, are likely to be responsible for the negative $B_{i s o}$ of V for SPS1083 and the very large $B_{\text {iso }}$ of S(1) as the simple structural model used fails to describe the structure accurately. Note that both $\mathrm{V}$ and $\mathrm{S}(1)$ atoms are involved in the $\left[\mathrm{VS}_{4}\right] \mathrm{Cu}_{6}$ complexes where the unrealistic $B_{\text {iso }}$ values occur. This is consistent with the presence of V-rich particles (see microscopy section) and the subsequent off-stoichiometry within the $\left[\mathrm{VS}_{4}\right] \mathrm{Cu}_{6}$ complexes. A more thorough investigation into the atomic structure using more powerful techniques such as synchrotron X-ray diffraction is necessary to fully describe the complex order-disorder relationship in V-Sn colusite, as demonstrated for $\mathrm{Cu}_{26-}$ ${ }_{x} \mathrm{Nb}_{2} \mathrm{Sn}_{6+x} \mathrm{~S}_{32}$. [24] Finally, the interatomic distances within the $\left[\mathrm{VS}_{4}\right] \mathrm{Cu}_{6}$ complex (Table S1) are increasing systematically with sintering temperature, consistent with the increase in the lattice parameter $a$. Overall, the refined data are consistent with our previous work and the level of disorder increases with the sintering temperature. Finally, while the refinements suggest a decrease in the overall crystallographic density, $d$ (Table S1), the presence of extra interstitial atoms, not taken into account by the model, is likely to compensate for the apparent decrease. Moreover, the measured geometrical density for SPS873, SPS1023, SPS1073 and SPS1083 were very constant with $4.42 \mathrm{~g} \mathrm{~cm}^{-3}, 4.41 \mathrm{~g} \mathrm{~cm}^{-3}, 4.45 \mathrm{~g} \mathrm{~cm}^{-3}$ and $4.46 \mathrm{~g} \mathrm{~cm}^{-3}$, respectively. In any case, these correspond to a geometrical density around $95 \%$ to $97 \%$ of the crystallographic value. 


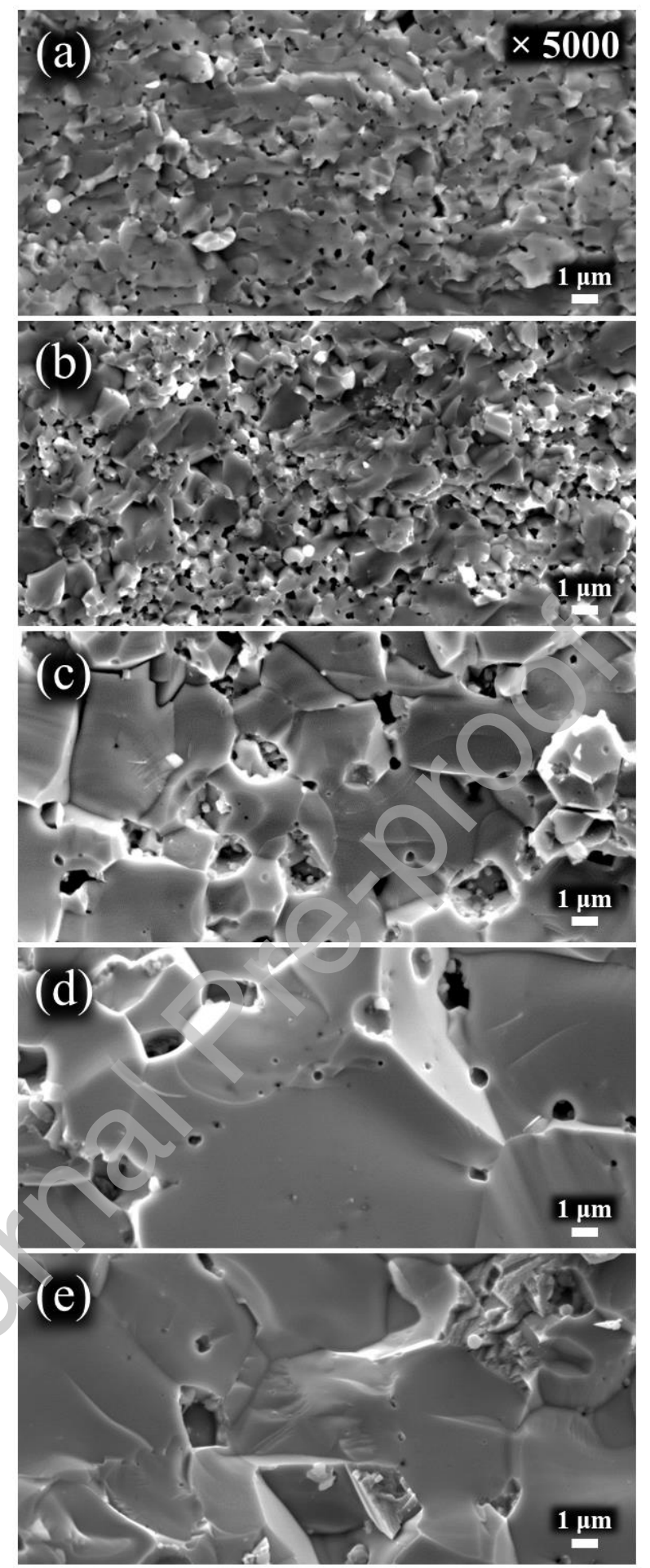

Figure 2. Scanning electron micrographs of a fractured surface of (a) the reference V-Sn colusite from elemental precursors (SPS, $873 \mathrm{~K}$ ) and V-Sn colusite samples from large batches of powders prepared using binary precursors and sintered using SPS at (b) $873 \mathrm{~K}$, (c) $1023 \mathrm{~K}$, (d) $1073 \mathrm{~K}$ and (e) $1083 \mathrm{~K}$. 
A combined TG/DSC analysis (Fig. 1d), carried out on compacted powders obtained from upscaled mechanical alloying (i.e. not sintered), gives valuable insights about the in-situ crystallization that occurs during the SPS process. Initially, a small exothermic signal centered at $672 \mathrm{~K}$, that may be attributed to the crystallization of the colusite phase and/or to thermal events linked with natural sintering, is followed by an endothermic signal centered at $729 \mathrm{~K}$ and a corresponding steep sulfur loss. This first onset of sulfur volatilization is unavoidable since much higher temperatures $(\geq 873 \mathrm{~K})$ are required to ensure good sintering and density. A clear endothermic peak centered at $1050 \mathrm{~K}$ occurs in association with another onset of sulfur volatilization. Finally, the curve exhibits a small endothermic peak at $1083 \mathrm{~K}$ followed by a large increase in the DSC signal, centered at $1097 \mathrm{~K}$, attributed to sample decomposition. In order to observe the impact of sulfur loss on the properties, the four samples were prepared at temperatures determined from these observed features. Note that the effects of pressure and heating/cooling rates during SPS on the reaction temperature determined by TG/DSC measurements were neglected considering that the real temperature during SPS is not known accurately. In particular, SPS1023 and SPS1073 are sintered at temperatures on each side of the endothermic peak centered at $1050 \mathrm{~K}$ while SPS1083 is sintered at only $10 \mathrm{~K}$ above SPS1073 but well within the sulfur loss region and very close to the large exothermic peak at $1097 \mathrm{~K}$.

Cationic disorder and crystallization are not the only consequences of higher sintering temperatures. Scanning electron micrographs (Fig. 2) show the evolution of grain size and morphology with sintering temperature for the four samples prepared from binary precursors in large batches, compared with the reference V-Sn colusite (SPS at $873 \mathrm{~K}$, elemental precursors). At first glance, SPS873 is somewhat similar to the reference material with a nonetheless broader particle size distribution. The more energetic milling conditions for the reference (600 rpm, $7 \mathrm{~g}, 12 \mathrm{~h}$ milling) and the nature of the precursors (elemental against 
binaries), despite yielding remarkably similar powders to the present work (Fig. S6) seems to promote a more homogeneous grain growth and sintering. Upon increasing the sintering temperature, it is clear from Figure 2 that a significant grain growth occurs and SPS1083 displays a fully dense, well-sintered microstructure. Notably, we can determine from the observed microstructure that a temperature higher than $1023 \mathrm{~K}$ is required to eliminate most submicron particles.
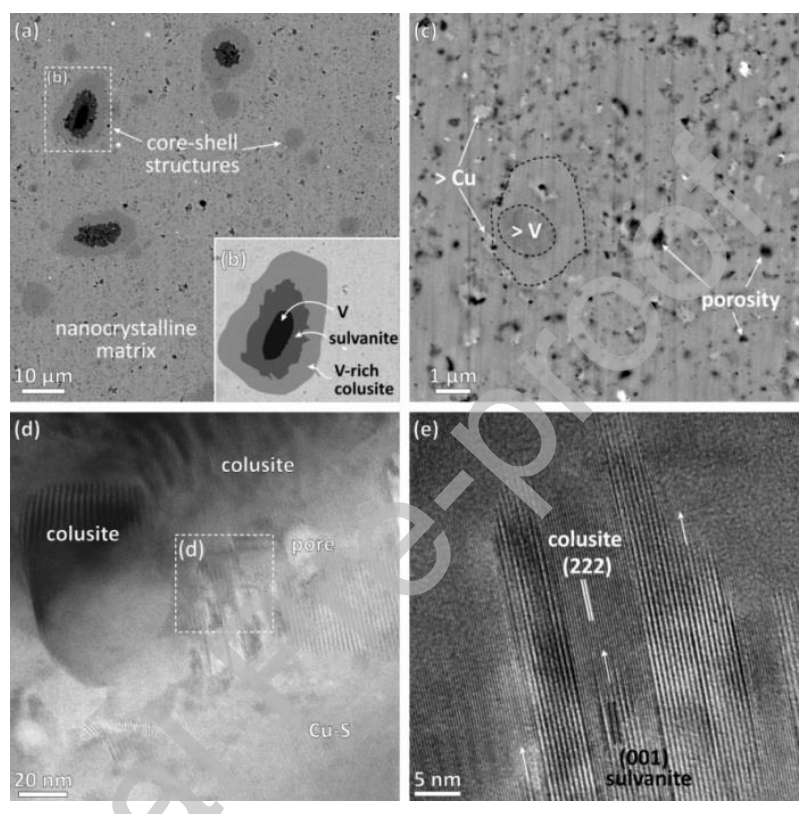

Figure 3. Microstructural analysis of SPS873: (a) Backscattered SEM image of polished surface showing V-rich core-shell structures within nanocrystalline matrix. (b) Magnified SEM image of nanocrystalline matrix with brighter $\mathrm{Cu}$-rich (> $\mathrm{Cu}$ ) nanoparticles embedded into the matrix with composition close to colusite indicating the presence of inhomogeneities at the nano level. (c) TEM image of the sample showing nanoparticles of colusite, $\mathrm{Cu}$-sulfide and the presence of sulvanite phase at the contact. (d) Oriented recrystallization of sulvanite to colusite with (001) sulvanite parallel to $(222)_{\text {colusite }}$.

For the following in-depth microstructural investigations, the samples sintered at the lowest and highest temperatures, respectively SPS873 and SPS1083, have been selected. Figure 3 
shows detailed microstructural analysis of the SPS873 sample. Backscattered SEM image (Fig. 3a) of the polished surface reveals the presence of inhomogeneities mainly related to incomplete distribution of vanadium in the sample. Vanadium was added to the initial powders in the form of metallic particles and during milling, some particles remained unreacted (Fig. S1). During SPS, they reacted with the surrounding Cu-sulfides, initially to the transient V-rich sulfide sulvanite, $\mathrm{Cu}_{3} \mathrm{VS}_{4}$, and further to V-rich and Sn-deficient colusite phase with chemical composition around " $\mathrm{Cu}_{26} \mathrm{~V}_{4} \mathrm{Sn}_{4} \mathrm{~S}_{32}$ " (V:Sn ratio of 1:1), and finally to the V-Sn colusite phase (Fig. S7-S8, Table S2). The results of this process are core-shell structures as shown in Figure 3a. Kinetic diffusion processes during reaction of metallic vanadium with the surrounding sulfides increase with temperature leading to a better distribution of vanadium throughout the sample. The short sintering time, in the case of SPS873, is not sufficient to form a completely homogenous microstructure. Note that fast reaction of metallic vanadium with $\mathrm{Cu}-\mathrm{Sn}-\mathrm{S}$ phases was already reported above $960 \mathrm{~K}$ from in situ neutron powder diffraction experiments.[49] In addition to vanadium, SEM/EDS analyses on SPS873 revealed inhomogeneous distribution of $\mathrm{Cu}$ in the nanocrystalline matrix surrounding the core-shell structures (Fig. S7-S8, Table S2). The SEM image of the polished microstructure taken at larger magnification (Fig. 3b) shows the presence of brighter nanosized particles within the matrix with dark gray contrast (the black regions are pores). The SEM/EDS analyses indicate that the matrix phase is colusite, but the composition varies due to the presence of inhomogeneities at the micro- (vanadium) and nano-scale (copper). TEM analyses of this sample have confirmed that the sample is composed of nanosized particles and mainly two types of particles with very different contrast were observed (Fig. 3 c, d). Colusite nanoparticles always give characteristic contrast resembling Moire fringes, which might be due to inhomogenous distribution of $\mathrm{V}$ and $\mathrm{Sn}$ within the colusite phase. Chemical composition of various colusite particles was inspected with TEM/EDS and the 
results showed composition with varying overall $\mathrm{V}+\mathrm{Sn}$ content and fairly constant V:Sn ratio of 1:3. Additionally, grains containing only $\mathrm{Cu}$ and $\mathrm{S}$ were found among the colusite particles. Quantification of the $\mathrm{Cu}: \mathrm{S}$ ratio was unreliable due to the additional $\mathrm{Cu}$ signal stemming from the brass ring (TEM sample support); however, composition close to 2:1 may be anticipated as traces amounts of $\mathrm{Cu}_{1.8} \mathrm{~S}$ where detected by XRPD in SPS873.

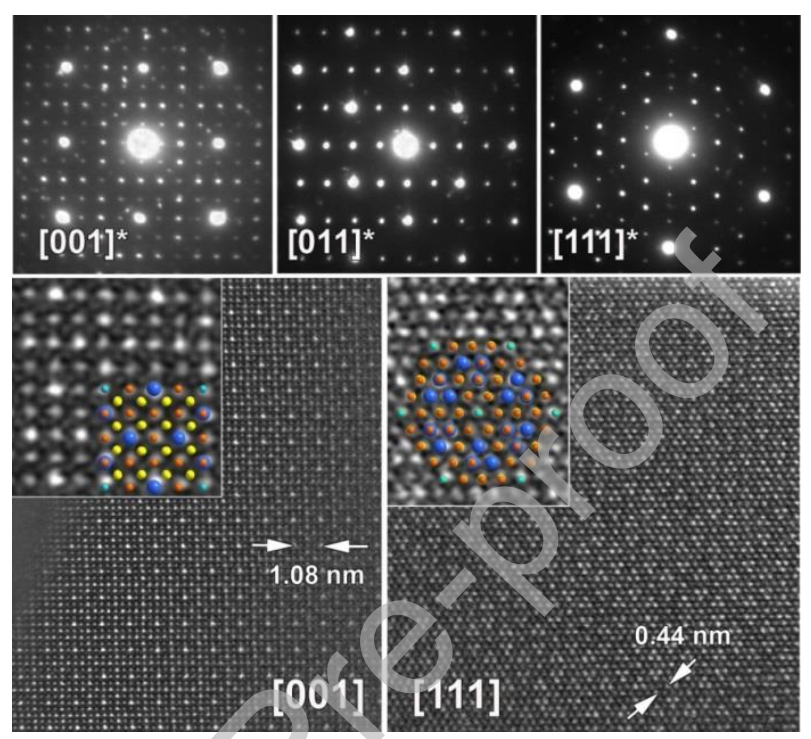

Figure 4. ED patterns of SPS873 collected for 3 main zone axis - [001]*, [011]* and [111]* confirming the cubic $P \overline{4} 3 n$ colusite structure (upper panel). The [001] and [111] HAADFSTEM images (bottom panel) show a well-ordered structure free of defects or secondary phase intergrowth. The magnified images with corresponding overlaid structural models are given as inset, with $\mathrm{Sn}, \mathrm{V}, \mathrm{Cu}$ and $\mathrm{S}$ atoms represented in dark blue, light blue, orange and yellow, respectively.

Polished microstructure of the SPS1083 sample reveals some residual porosity (Fig. S9a) and SEM/EDS analyses did not show variations in the chemical composition of colusite at the micro-level. TEM analysis (Fig. S9b and Fig. S10) has shown that colusite grains have constant average chemical composition with the expected V:Sn ratio; however, distribution of 
both elements within colusite lattice might be locally inhomogeneous. TEM/EDS analysis of grain boundaries did not reveal any local segregation.

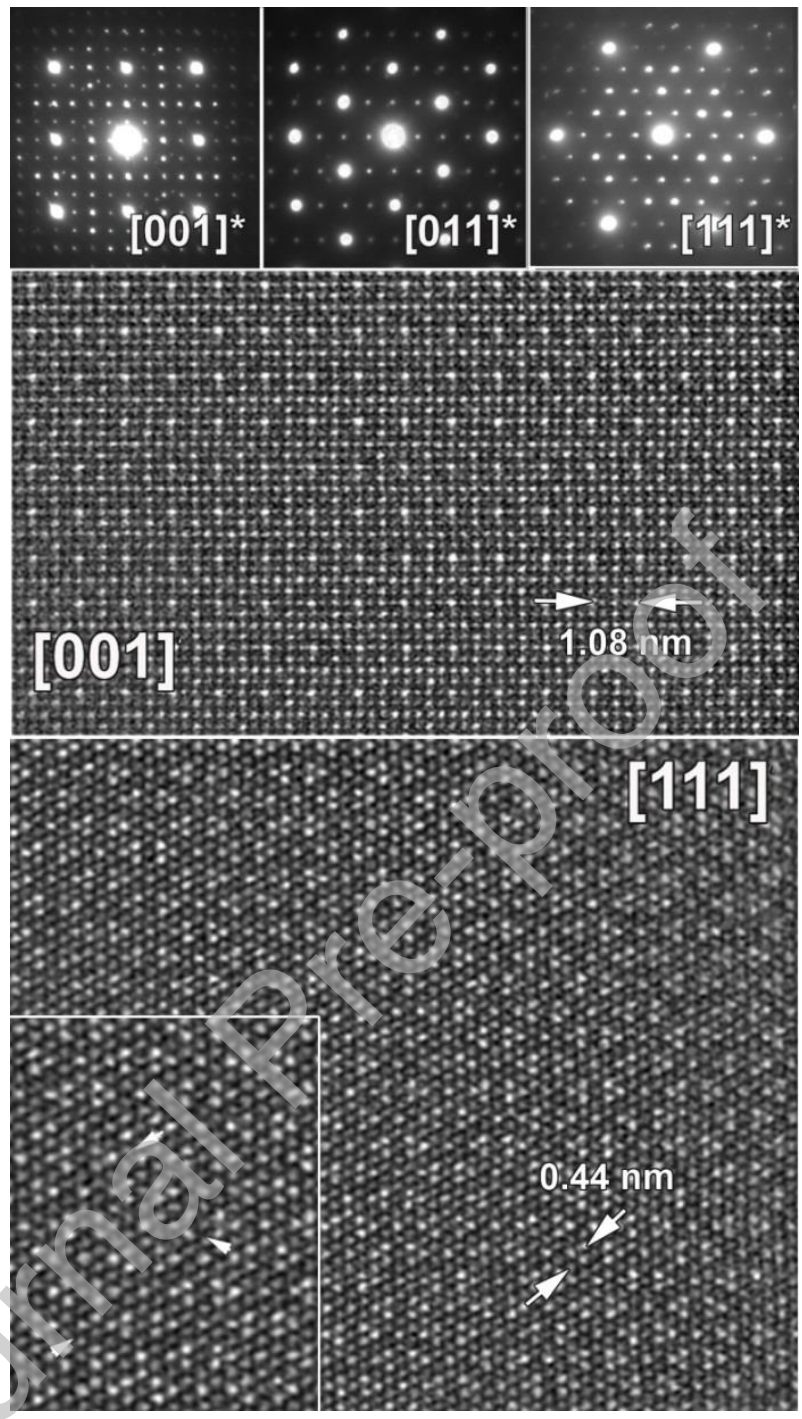

Figure 5. ED patterns of SPS1083 collected for 3 main zone axis - [001]*, [011]* and [111]* confirming cubic $P \overline{4} 3 n$ colusite structure (upper panel). The [001] and [111] HAADF-STEM images (bottom panel) show an overall good crystallinity with the presence of disordered regions evidenced by a lower brightness for Sn columns. An enlargement [111] image is given as inset where cationic disordered areas depicted by white arrows.

Finally, the level of cationic disorder, crucial in order to explain the thermal transport properties,[18] has been investigated using transmission electron microscopy (TEM), 
including electron diffraction analysis (ED) and high-angular annular dark field scanning TEM (HAADF-STEM). Figure 4 shows the ED patterns of SPS873 collected for three main zone axis, i.e. [001], [011] and [111]. All patterns are matching with colusite $\mathrm{Cu}_{26} \mathrm{~V}_{2} \mathrm{Sn}_{6} \mathrm{~S}_{32}$ structure (space group $P \overline{4} 3 n$ ). No superstructure spots, streaks or spots distortion due to possible long range order/disorder, or extended defects are present. The high resolution HAADF-STEM imaging along two most informative [001] and [111] zone axes (Fig. 4, bottom panel) of colusite confirmed the expected highly ordered structure with no apparent defect or cationic disorder. The enlarged images (Fig. 4, bottom panel insets) with overlaid structural model shows good matching of all atomic columns with an experimental image, where the brightest dots in HAADF-STEM image correspond to $\mathrm{Sn}(\mathrm{Z}=50)$ and less bright to $\mathrm{Cu}(\mathrm{Z}=29)$ and $\mathrm{V}(\mathrm{Z}=23)$ atoms. The ED analysis of SPS1083 (Fig. 5, upper panel) does not show a significant difference from the ED patterns of SPS873. However, the high resolution HAADF-STEM images, in spite of the good overall level of ordering, exhibit some local atomic cationic disordered regions. The careful analysis of [111] HAADF-STEM image revealed a recognizable reduction in brightness for the $\mathrm{Sn}$ atomic column (Fig. 5, bottom panel inset) suggesting cationic inhomogeneity within $\mathrm{Sn}$ atomic column as it was reported previously.[18] Moreover, HAADF-STEM studies of grain boundaries evidence preferential localization and segregation such as high levels of cationic disorder along the interface region. Figure 6 shows high resolution HAASDF-STEM image of one of the grain boundaries in SPS1083. The interface is very sharp and no secondary phase or amorphous layers were detected. The right grain in Figure 6 is oriented along the [001] zone axis and exhibits contrasts typical for colusite structure HAADF-STEM images along this particular zone axis (See Fig. 4). However, besides well-ordered areas (Fig. 6c), some cationic disorder (Fig. 6a, b) can be clearly distinguished. They are located along the grain boundaries and initiated from the interface. 


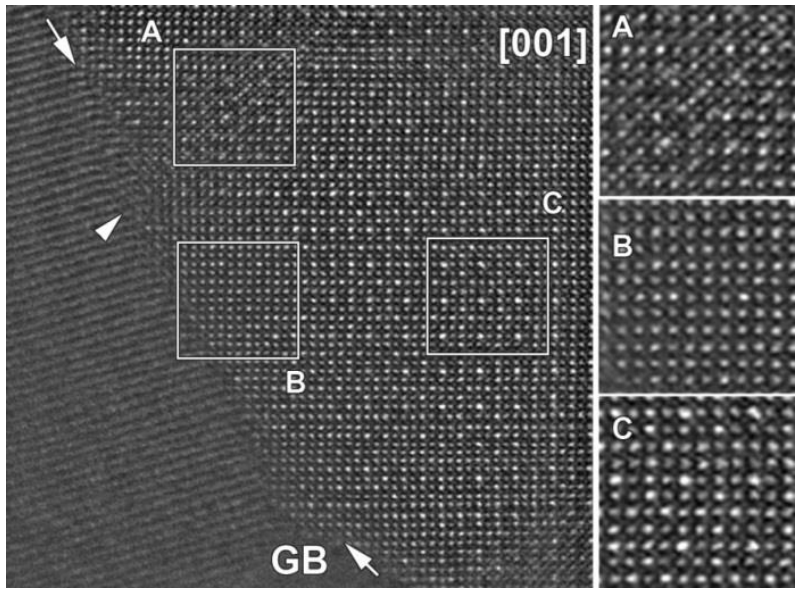

Figure 6. High resolution HAADF-STEM image of GB (marked by white arrow) in SPS1083 viewing along [001] zone axis of one of the grain (right of GB). Three regions can be clearly distinguished in the image: well-ordered colusite (region C), and two regions exhibiting different levels of cationic disorder (regions A and B). The magnified images of each area are given as inset in the right panel.

In order to get more insight into the level of disorder arising from $\mathrm{Sn}$-site defects, ${ }^{119} \mathrm{Sn}$ Mössbauer spectra were recorded at room temperature for SPS873 and SPS1083 (Fig. S11). In both cases, the spectra exhibit a narrow quadrupolar doublet but with slightly different hyperfine parameters. The values of the isomer shift $(\delta)$ deduced from the fit are $1.35 \pm 0.01$ $\mathrm{mm} \mathrm{s}^{-1}$ and $1.45 \pm 0.01 \mathrm{~mm} \mathrm{~s}^{-1}$ for SPS873 and SPS1083, respectively. These values are characteristic of tin atoms in a +IV oxidation state. The value of the quadrupole splitting is also slightly enhanced for $\operatorname{SPS} 1083\left(\Delta \mathrm{E}_{\mathrm{Q}}=0.46 \pm 0.03 \mathrm{~mm} \mathrm{~s}^{-1}\right)$ compared to $\operatorname{SPS} 873\left(\Delta \mathrm{E}_{\mathrm{Q}}=\right.$ $\left.0.29 \pm 0.08 \mathrm{~mm} \mathrm{~s}^{-1}\right)$. The same trend is observed for the full width at half-maximum of the lines, which is higher for SPS1083 $\left(\Gamma=1.18 \pm 0.04 \mathrm{~mm} \mathrm{~s}^{-1}\right)$ than SPS873 $(\Gamma=1.02 \pm 0.09$ $\mathrm{mm} \mathrm{s}^{-1}$ ). This broadening of the Lorentzian lines of the quadrupolar doublet indicates a higher level of disorder of the crystal structure after the high temperature treatment. Note that adding a doublet (5\% of total spectral area, pink curve in Fig. S11) attributed to a small amount of impurity improves slightly the fit of the spectrum in case of SPS873. This is consistent with 
the presence of unreacted vanadium and subsequent off-stoichiometry that leads to the presence of small regions of different compositions.

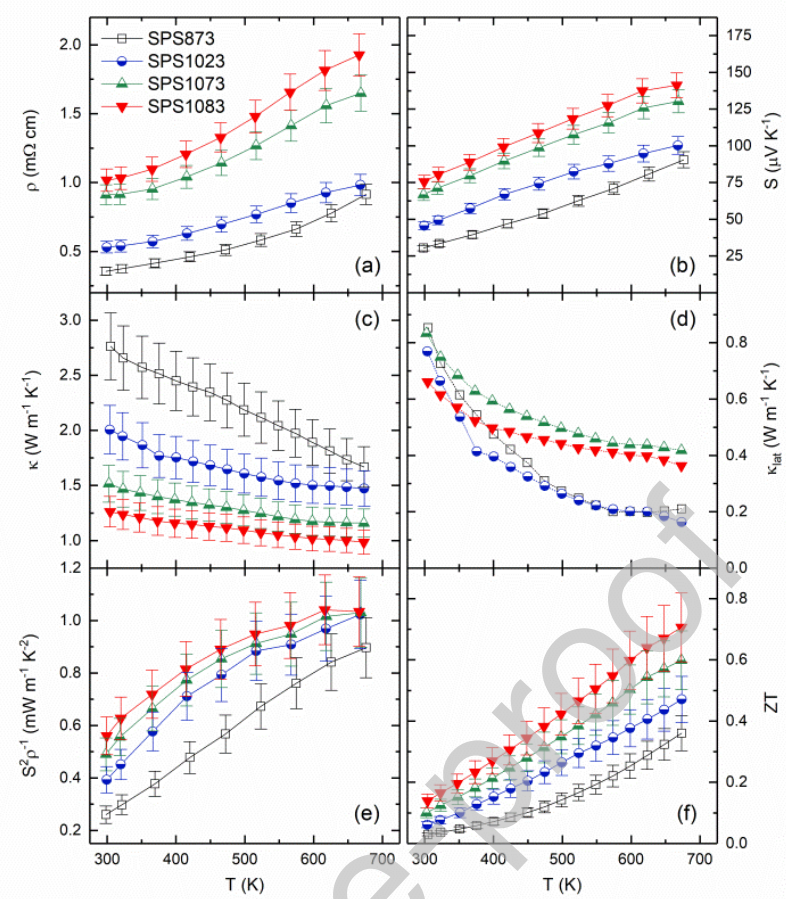

Figure 7. Temperature dependence of (a) electrical resistivity, $\rho$, (b) Seebeck coefficient, $S$, (c) thermal conductivity, $\kappa$, (d) lattice contribution to the thermal conductivity, $\kappa_{\text {lat }}$, (e) power factor, $S^{2} \rho^{-1}$, and (f) figure of merit, $\mathrm{ZT}$, for $\mathrm{Cu}_{26} \mathrm{~V}_{2} \mathrm{Sn}_{6} \mathrm{~S}_{32}$ prepared from binary precursors and sintered using SPS at $873 \mathrm{~K}, 1023 \mathrm{~K}, 1073 \mathrm{~K}$ and $1083 \mathrm{~K}$.

\subsection{Electrical properties}

The electrical properties of the V-Sn colusite samples prepared from binary and sintered at various temperatures (SPS873 $\rightarrow$ SPS1083) are displayed in Figure 7(a, b, e). The characteristic behavior of the electrical resistivity for all samples is metallic over the investigated temperature range. For the samples subjected to milder sintering conditions, SPS873 and SPS1023, the electrical resistivity retains a metallic behavior across the whole investigated temperature range, characteristic of ordered colusite. However, SPS1073 and SPS1083 exhibit slightly different temperature dependences with a distinctive "S" shape, as 
observed previously in $\mathrm{Cu}_{26} \mathrm{Cr} \mathrm{Ge}_{6} \mathrm{~S}_{32}(T=\mathrm{Mo}, \mathrm{W})$.[20] This somewhat characteristic shape has been linked to a change in transport mechanism caused by the level of disorder and its impact on the Cu-S conduction network.[20] Concurrently, the Seebeck coefficient for all samples retains similar temperature dependence and positive value, i.e. $p$-type character, as well as evidencing a decrease in the hole concentration with sintering temperature, confirmed by Hall effect measurements at room temperature (Table 1). This decrease along with the electrical resistivity behavior are consistent with sulfur loss and the accompanying cationic disorder and cation self-intercalation in tetrahedral positions similar to the $2 a$ site occupied by V. This type of disorder drives the crystal structure away from that of ideal colusite and can be linked to the aberrant values of atomic displacement observed in the Rietveld refinements of PXRD data (Table S1). Overall, as the sintering temperature rises, the stoichiometry of the colusite phase furthers from the nominal composition and drives the transport properties towards a more semiconducting state. As a result, the sample with the highest electrical resistivity, namely SPS1083 with $\rho=1.02 \mathrm{~m} \Omega \mathrm{cm}$ and $\rho=1.93 \mathrm{~m} \Omega \mathrm{cm}$ at $300 \mathrm{~K}$ and $663 \mathrm{~K}$ respectively, also exhibits the highest Seebeck coefficient with $S=76 \mu \mathrm{V} \mathrm{K}^{-1}$ and $S=141 \mu \mathrm{V}$ $\mathrm{K}^{-1}$ at $300 \mathrm{~K}$ and $663 \mathrm{~K}$ respectively (Fig. 7(a, b)). Consequently, the improved Seebeck coefficient more than compensates for the increase in electrical resistivity and the resulting power factor, $S^{2} / \rho$, is improved with a maximum value of $1.04 \mathrm{~mW} \mathrm{~m}^{-1} \mathrm{~K}^{-2}$ at $663 \mathrm{~K}$ compared with the previously reported maximum of $c a .0 .77 \mathrm{~mW} \mathrm{~m}^{-1} \mathrm{~K}^{-2}$ at $673 \mathrm{~K}$ for labscale V-Sn colusite.[18] Note that the electrical transport properties for the present samples are largely improved over the reported lab-scale V-Sn colusite regardless of the sintering temperature. The comparatively lower electrical resistivity at similar Seebeck coefficients for samples prepared from industrial binary precursors can be partly explained by the larger grain size. In addition, the presence of the vanadium-rich core-shell structures may also play a role in the transport property discrepancies with high purity lab-scale samples. 
Table 1. Room temperature charge carrier concentration, $n_{h+}$, electrical resistivity, $\rho$, carrier mobility, $\mu$, and effective mass, $m * / m_{o}$ for $\mathrm{Cu}_{26} \mathrm{~V}_{2} \mathrm{Sn}_{6} \mathrm{~S}_{32}$ at different sintering temperatures.

\begin{tabular}{ccccc}
\hline $\mathrm{T}_{\text {SPS }}(\mathrm{K})$ & $n_{\mathrm{h}+}\left(\times 10^{21} \mathrm{~cm}^{-3}\right)$ & $\rho_{300 \mathrm{~K}}(\Omega \mathrm{m})$ & $\mu_{300 \mathrm{~K}}\left(\mathrm{~cm}^{2} \mathrm{~V}^{-1} \mathrm{~s}^{-1}\right)$ & $\mathrm{m}^{*} / \mathrm{m}_{\circ}$ \\
\hline 873 & 6.56 & $3.56 \times 10^{-6}$ & 2.68 & 5.3 \\
1023 & 5.81 & $5.31 \times 10^{-6}$ & 2.02 & 7.3 \\
1073 & 5.66 & $9.12 \times 10^{-6}$ & 1.21 & 10.6 \\
1083 & 4.45 & $10.2 \times 10^{-6}$ & 1.38 & 10.2 \\
\hline
\end{tabular}

From Hall effect measurements at $300 \mathrm{~K}$ (Table 1), we observe a decrease in the carrier mobility, $\mu$, with sintering temperature that can be explained by the higher cationic disorder, confirmed by HAADF-STEM (Fig. 4-6) and ${ }^{119}$ Sn Mossbauer Spectroscopy (Fig. S11). However, this decrease is only significant up to SPS1073 and the mobility varies only marginally for SPS1083. By using the single parabolic band model approximation for acoustic phonon scattering,[50,51] we can qualitatively compare the effective mass of the charge carriers as function of sintering temperature:

$$
S=\frac{8 \pi^{2} k_{B}}{3 e h^{2}}\left(\frac{\pi}{3 n_{\mathrm{h}+}}\right)^{2 / 3} m^{*} T
$$

(equation 1)

where $S$ is the Seebeck coefficient, $k_{\mathrm{B}}$ the Boltzmann constant, $h$ the Planck constant, $e$ the electron charge, $n_{\mathrm{h}+}$ the carrier concentration, $m^{*}$ the effective mass, and $T$ is the absolute temperature. Nevertheless, the obtained values for the effective mass (Table 1) must be considered with a healthy amount of caution as this very simplified model might not give an accurate depiction of the complex transport behavior of colusite. In particular, we know that the conduction mechanism in the related colusite $\mathrm{Cu}_{26} \mathrm{Cr}_{2} \mathrm{Ge}_{6} \mathrm{~S}_{32}$ can change dramatically with only but a slight variation in the cationic arrangement, from acoustic phonon scattering to a impurity scattering-like mechanism.[19,20] Nonetheless, we can observe that, up to $1073 \mathrm{~K}$, a higher sintering temperature causes a reduction in charge carrier concentration and is accompanied by a decrease in the mobility and an increase in the effective mass of the charge carriers (Fig. S12). For SPS1083, these changes are less significant and might be evidencing a 
competition of effects between grain growth, disorder and the disappearance of the vanadium core-shell structures, resulting in a minimum in charge carrier mobility for SPS1073.

\subsection{Thermal properties}

The principal objective behind sintering at higher temperature was to decrease the thermal conductivity via the synergistic effects of sulfur loss and structural disorder, i.e. reducing the electronic and lattice contributions, respectively. This was particularly efficient when labscale V-Sn colusite was sintered in a hot-press for over an hour at $1023 \mathrm{~K}$, leading to a large decrease in the total thermal conductivity from $c a \cdot 2.1-2.9$ to $c a .0 .6 \mathrm{~W} \mathrm{~m}^{-1} \mathrm{~K}^{-1}$ at $675 \mathrm{~K}$.[18] Surprisingly, such drastic reduction was not observed here (Fig. $7(\mathbf{c}, \mathbf{d}))$, even at sintering temperatures as high as $1083 \mathrm{~K}$, with a minimum $\kappa$ of $c a .1 \mathrm{~W} \mathrm{~m}^{-1} \mathrm{~K}^{-1}$ at $673 \mathrm{~K}$ for SPS1083; a value about $40 \%$ higher than the disordered lab-scale hot-pressed colusite previously reported. The unit cell parameter, $a$, is a good indicator of the level of disorder as it reflects the extent of sulfur loss.[18,24] Here, the largest unit cell parameter is expectedly obtained for SPS1083 with a value of 10.8081(1) A that, despite a significant increase over stoichiometric V-Sn colusite ( $a=10.7657(1)$ in this work and $a=10.7701(2)$ in ref 17), remains quite smaller than the highly disorder V-Sn colusite reported previously with $a=10.8289(2) \AA .[18]$ This suggests that the present synthesis and sintering conditions are slightly less efficient in generating structural disorder. Meanwhile, a significant reduction was obtained in the electronic contribution to the thermal conductivity (Fig. S13), which led to a systematic reduction in the total thermal conductivity with sintering temperature over the whole investigated temperature range.

Despite the lower sintering temperature, the amplitude of the lattice thermal conductivity at high temperature is lower than expected for SPS873 and SPS1023 samples, with values consistent with disordered V-Sn colusite and reaching a $\kappa_{\text {lat }}$ around the theoretical minimum of $0.27 \mathrm{~W} \mathrm{~m}^{-1} \mathrm{~K}^{-1}$.[18] The consequence is an increase in this lattice contribution with 
sintering temperature for SPS1073 and SPS1083 in contradiction to the strong expected reduction from temperature-induced defect formation. While the smaller-than-expected unit cell parameter $a$ for samples sintered at $1073 \mathrm{~K}$ and $1083 \mathrm{~K}$ suggests a lower level of disorder, it does not suffice to explain the increased $\kappa_{\text {lat }}$ observed between samples sintered at these temperatures. Instead, the increased lattice contribution with sintering temperature is explained by the substantial grain growth evidenced in Figure 2 and the disappearance of the nano-microsize defects (Fig. 2, 3, S9) that are likely to provide additional phonon scattering centers. Additionally, and despite a relatively small sintering temperature difference between SPS1023, SPS1073 and SPS1083, a clear change in the amplitude of the lattice thermal conductivity is consistent with the disappearance of the defects and submicron particles as observed in the previous section. These observations are also strengthened by the TG/DSC analyses that clearly identified a thermal event at $1050 \mathrm{~K}$ that can be related to an onset of sulfur loss and a rapid grain growth. Indeed, the thermal event occurring at around $1050 \mathrm{~K}$ can therefore be held responsible for the larger particle size and the complete crystallization of colusite from the vanadium core-shell structures. In samples prepared from high purity elements, such core-shell structures were not observed.[18] Hence, their formation is attributed to the use of binary precursors that quickly form a sphalerite-like pseudo-crystalline matrix with distributed vanadium metal particles that diffuse partially at $873 \mathrm{~K}$ and are fully reacted at $1083 \mathrm{~K}$. An investigation into the kinetic aspect of the sintering of V-Sn colusite is currently on-going in order to explain the impact of sintering time on the formation/disappearance of the vanadium-rich core-shell structures and grain-growth.

As a result of the simultaneous increase in power factor and decrease in the thermal conductivity, SPS1083 exhibits a maximum $Z T$ value of $c a .0 .7$ at $673 \mathrm{~K}$ and a $Z T_{\text {avg }}$ of 0.41 over the $300 \mathrm{~K}-673 \mathrm{~K}$ range, a nearly factor 3 improvement over SPS873 with a $Z T_{\text {avg }}$ of 0.15 (Fig. 7f). While this performance remains slightly below that of the lab-scale disordered V-Sn 
colusite with a ZT of $c a .0 .9$ at $675 \mathrm{~K}$, it is a small loss considering the use of a scale-up process and cheap industrial-grade binary precursors. Additionally, the power factor was significantly improved by ca. $30 \%$ over that of lab-scale V-Sn or Ta-Sn colusite over the whole temperature range. This is in itself quite desirable as the overall output power density of the thermoelectric device depends on the power factor. These electrical performances are, to date, the best amongst germanium-free colusites whether we compare the maximum power factor or the average power factor over the temperature range $300 \leq T$ / $\mathrm{K} \leq 650 \mathrm{~K}$ (Fig. 8).

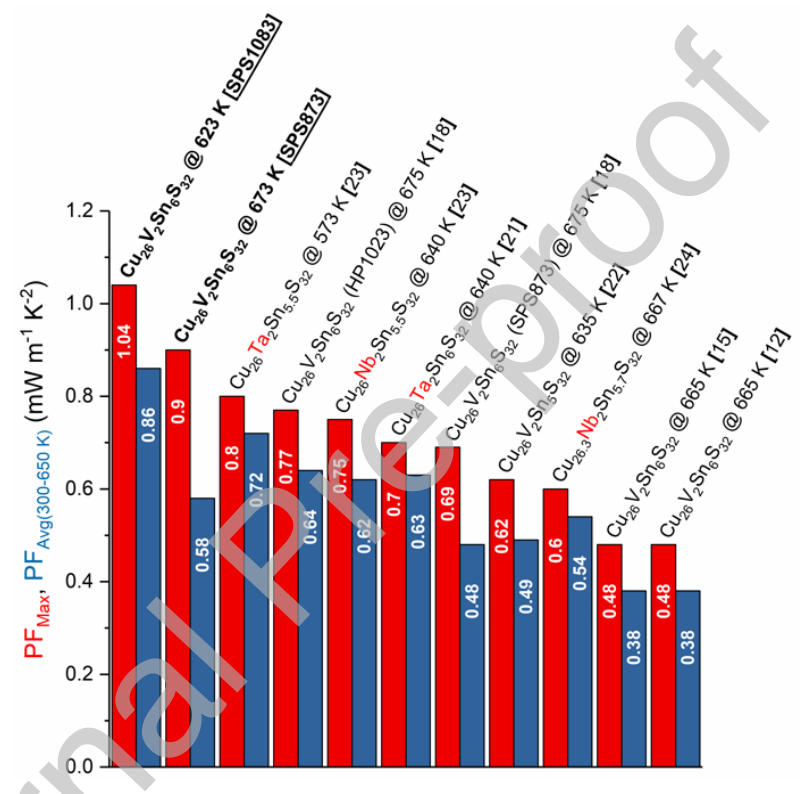

Figure 8. Comparison of the electrical performances of SPS873 and SPS1083 from this work with the reported germanium-free colusites to date. The maximum power factor at the specified temperature, $P F_{M a x}$, and the average power factor, $P F_{A v g}$, over the temperature range $300 \leq T / \mathrm{K} \leq 650 \mathrm{~K}$ are given in red and blue respectively. Each label corresponds to the best performing composition of each investigated series within the stated references.

Overall, careful consideration of the thermal events in the in-situ crystallization of colusite during SPS was successful in improving the thermoelectric performance of cost-efficient VSn colusite and the mechanisms behind the formation of colusite from binary precursors have been investigated. Indeed, while the cationic disorder and carrier concentration optimization 
have led to the highest $Z T$ values in this study, the extremely low lattice thermal conductivity observed in SPS873, achieved by defect engineering through rapid crystallization of colusite around vanadium-rich core-shell structures and by retaining submicron particles, is among the lowest observed in optimized thermoelectric sulfides (Fig. 9).

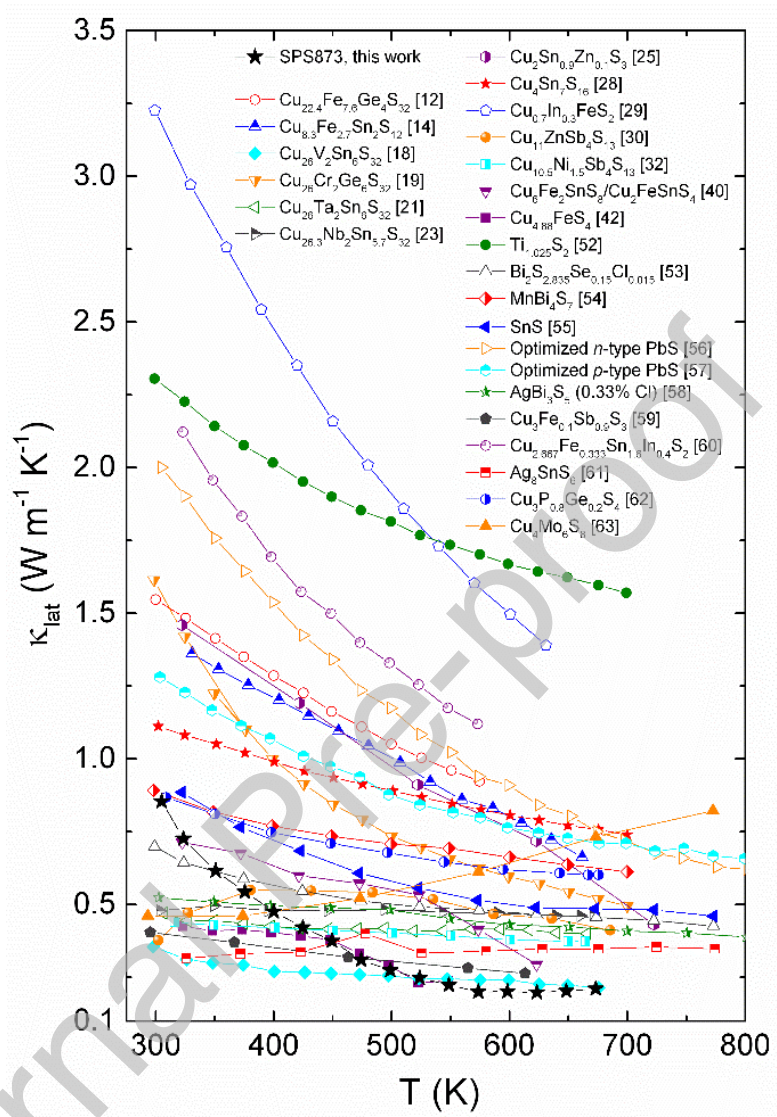

Figure 9. Comparison between the estimated lattice contribution to the thermal conductivity of SPS873 with reported values from notable, state-of-the-art, thermoelectric sulfides up to $800 \mathrm{~K}$. Values for the best performing composition were selected when available. Data adapted from $[12,14,18,19,21,24,25,28-30,32,40,42,52-63]$. 


\section{Conclusion}

We successfully produced large batches of the performing thermoelectric colusite, $\mathrm{Cu}_{26} \mathrm{~V}_{2} \mathrm{Sn}_{6} \mathrm{~S}_{32}$, using up-scaled mechanical alloying with optimized milling conditions and SPS process. Despite the use of industrial grade metal sulfides, samples with excellent purity and reproducibility have been obtained. In-depth microstructural analysis has been carried out in order to explain the discrepancies in the thermoelectric performance between high-purity lab-scale V-Sn colusite and the present samples. The main difference, namely the ultralow lattice thermal conductivity down to the theoretical minimum for SPS873, is attributed to the presence of nano-microsize defects. These defects arise from the incomplete crystallization of the colusite phase and provide additional phonon scattering centers. In particular, the presence of vanadium core-shell structures gives additional insights into the formation mechanism of colusite from binary precursors. At higher sintering temperature, the induced cationic disorder and sulfur-deficiency lead to an overall improvement of the thermoelectric performance compared with lower sintering temperatures with the highest reported power factor in germanium-free colusite and a maximum $Z T$ value of $c a .0 .7$ at $673 \mathrm{~K}$ and a $Z T_{\text {avg }}$ of 0.41 over the temperature $\mathrm{K}$ range $300 \leq T / \mathrm{K} \leq 673 \mathrm{~K}$ for SPS1083. In other less metallic phases involving similar vanadium diffusion as part of the crystallization, low lattice thermal conductivity may be achieved by promoting the formation of vanadium core-shell structures.

\section{Acknowledgements}

The authors would like to thank Christelle Bilot and Jerôme Lecourt for technical support. This work was supported by the French Agence Nationale de la Recherche (ANR) through the programs Energy Challenge for Secure, Clean and Efficient Energy (Challenge 2, 2015, ANR-15-CE05-0027) and Institut CARNOT ESP, FEDER and Normandy Region. The authors would like to extend their thanks to Tribotecc for supplying large amounts of 
industrial grade precursors. N.D. acknowledges financial support from the Slovenian Research Agency in the frame of the research project J1-9177.

\section{Declaration of interests}

The authors declare that they have no known competing financial interests or personal relationships that could have appeared to influence the work reported in this paper.

\section{References:}

[1] I.T. Witting, T.C. Chasapis, F. Ricci, M. Peters, N.A. Heinz, G. Hautier, G.J. Snyder, The Thermoelectric Properties of Bismuth Telluride, Adv. Electron. Mater. 5 (2019) 1800904. https://doi.org/10.1002/aelm.201800904.

[2] J. He, T.M. Tritt, Advances in thermoelectric materials research: Looking back and moving forward, Science 357 (2017) eaak9997. https://doi.org/10.1126/science.aak9997.

[3] C.B. Vining, An inconvenient truth about thermoelectrics, Nat. Mater. 8 (2009) 83. https://doi.org/10.1038/nmat2361.

[4] G. Min, D.M. Rowe, Chapter 38. Peltier Devices as Generators, in: D.M. Rowe (Ed.), CRC Handb. Thermoelectr., CRC Press, 1995.

[5] S. Ohno, K. Imasato, S. Anand, H. Tamaki, S.D. Kang, P. Gorai, H.K. Sato, E.S. Toberer, T. Kanno, G.J. Snyder, Phase Boundary Mapping to Obtain n-type $\mathrm{Mg}_{3} \mathrm{Sb}_{2}-$ Based Thermoelectrics, Joule. 2 (2018) 141-154. https://doi.org/10.1016/j.joule.2017.11.005. 
[6] D. Cheikh, B.E. Hogan, T. Vo, P. Von Allmen, K. Lee, D.M. Smiadak, A. Zevalkink, B.S. Dunn, J.-P. Fleurial, S.K. Bux, Praseodymium Telluride: A High-Temperature, High-ZT Thermoelectric Material, Joule. 2 (2018) 698-709. https://doi.org/10.1016/j.joule.2018.01.013.

[7] J.R. Sootsman, D.Y. Chung, M.G. Kanatzidis, New and old concepts in thermoelectric materials, Angew. Chemie - Int. Ed. 48 (2009) 8616-8639. https://doi.org/10.1002/anie.200900598.

[8] X. Hu, P. Jood, M. Ohta, M. Kunii, K. Nagase, H. Nishiate, M.G. Kanatzidis, A. Yamamoto, Power generation from nanostructured $\mathrm{PbTe}$-based thermoelectrics: comprehensive development from materials to modules, Energy Environ. Sci. 9 (2016) 517-529. https://doi.org/10.1039/C5EE02979A.

[9] P. Qiu, T. Zhang, Y. Qiu, X. Shi, L. Chen, Sulfide bornite thermoelectric material: A natural mineral with ultralow thermal conductivity, Energy Environ. Sci. 7 (2014) 4000-4006. https://doi.org/10.1039/c4ee02428a.

[10] G. Guélou, A.V.Powell, P. Vaqueiro, Ball milling as an effective route for the preparation of doped bornite: Synthesis, stability and thermoelectric properties, J. Mater. Chem. C. 3 (2015) 10624-10629. https://doi.org/10.1039/c5tc01704a.

[11] V. Pavan Kumar, T. Barbier, P. Lemoine, B. Raveau, V. Nassif, E. Guilmeau, The crucial role of selenium for sulphur substitution in the structural transitions and thermoelectric properties of $\mathrm{Cu}_{5} \mathrm{FeS}_{4}$ bornite, Dalt. Trans. 46 (2017) 2174-2183. https://doi.org/10.1039/c6dt04204j.

[12] V. Pavan Kumar, L. Paradis-Fortin, P. Lemoine, V. Caignaert, B. Raveau, B. Malaman, G. Le Caër, S. Cordier, E. Guilmeau, Designing a Thermoelectric Copper-Rich Sulfide 
from a Natural Mineral: Synthetic Germanite $\mathrm{Cu}_{22} \mathrm{Fe}_{8} \mathrm{Ge}_{4} \mathrm{~S}_{32}$, Inorg. Chem. 56 (2017) 13376-13381. https://doi.org/10.1021/acs.inorgchem.7b02128.

[13] V. Pavan Kumar, L. Paradis-Fortin, P. Lemoine, G. Le Caer, B. Malaman, P. Boullay, B. Raveau, G. Guélou, E. Guilmeau, Crossover from germanite to renierite-type structures in $\mathrm{Cu}_{22-\mathrm{x}} \mathrm{Zn}_{\mathrm{x}} \mathrm{Fe}_{8} \mathrm{Ge}_{4} \mathrm{~S}_{32}$ thermoelectric sulfides, ACS Appl. Energy Mater. 2 (2019) 7679-7689. https://doi.org/https://doi.org/10.1021/acsami.0c00094.

[14] V. Pavan Kumar, T. Barbier, V. Caignaert, B. Raveau, R. Daou, B. Malaman, G. Le Caër, P. Lemoine, E. Guilmeau, Copper Hyper-Stoichiometry: The Key for the Optimization of Thermoelectric Properties in Stannoidite $\mathrm{Cu}_{8+\mathrm{x}} \mathrm{Fe}_{3-\mathrm{x}} \mathrm{Sn}_{2} \mathrm{~S}_{12}$, J. Phys. Chem. C. 121 (2017) 16454-16461. https://doi.org/10.1021/acs.jpcc.7b02068.

[15] K. Suekuni, F.S. Kim, H. Nishiate, M. Ohta, H.I. Tanaka, T. Takabatake, Highperformance thermoelectric minerals: Colusites $\mathrm{Cu}_{26} \mathrm{~V}_{2} \mathrm{M}_{6} \mathrm{~S}_{32}(\mathrm{M}=\mathrm{Ge}, \mathrm{Sn})$, Appl. Phys. Lett. 105 (2014) 132107. https://doi.org/10.1063/1.4896998.

[16] K. Suekuni, F.S. Kim, T. Takabatake, Tunable electronic properties and low thermal conductivity in synthetic colusites $\mathrm{Cu}_{26-\mathrm{x}} \mathrm{Zn}_{\mathrm{x}} \mathrm{V}_{2} \mathrm{M}_{6} \mathrm{~S}_{32}(\mathrm{x} \leq 4, \mathrm{M}=\mathrm{Ge}, \mathrm{Sn}), \mathrm{J}$. Appl. Phys. 116 (2014) 063706. https://doi.org/10.1063/1.4892593.

[17] C. Bourgès, M. Gilmas, P. Lemoine, N.E. Mordvinova, O.I. Lebedev, E. Hug, V. Nassif, B. Malaman, R. Daou, E. Guilmeau, Structural analysis and thermoelectric properties of mechanically alloyed colusites, J. Mater. Chem. C. 4 (2016) 7455-7463. https://doi.org/10.1039/C6TC02301K.

[18] C. Bourgès, Y. Bouyrie, A.R. Supka, R. Al Rahal Al Orabi, P. Lemoine, O.I. Lebedev, M. Ohta, K. Suekuni, V. Nassif, V. Hardy, R. Daou, Y. Miyazaki, M. Fornari, E. Guilmeau, High-Performance Thermoelectric Bulk Colusite by Process Controlled 
Structural Disordering, J. Am. Chem. Soc. 140 (2018) 2186-2195.

https://doi.org/10.1021/jacs.7b11224.

[19] V. Pavan Kumar, A.R. Supka, P. Lemoine, O.I. Lebedev, B. Raveau, K. Suekuni, V. Nassif, R. Al Rahal Al Orabi, M. Fornari, E. Guilmeau, High Power Factors of Thermoelectric Colusites $\mathrm{Cu}_{26} \mathrm{~T}_{2} \mathrm{Ge}_{6} \mathrm{~S}_{32}(\mathrm{~T}=\mathrm{Cr}, \mathrm{Mo}, \mathrm{W})$ : Toward Functionalization of the Conductive "Cu-S" Network, Adv. Energy Mater. 9 (2019) 1803249. https://doi.org/10.1002/aenm.201803249.

[20] V. Pavan Kumar, G. Guélou, P. Lemoine, B. Raveau, A. Supka, R. Al Rahal Al Orabi, M. Fornari, K. Suekuni, E. Guilmeau, Copper-rich thermoelectric sulfides: size mismatch effect and chemical disorder in the $\left[\mathrm{TS}_{4}\right] \mathrm{Cu}_{6}$ complexes of $\mathrm{Cu}_{26} \mathrm{~T}_{2} \mathrm{Ge}_{6} \mathrm{~S}_{32}(\mathrm{~T}$ $=\mathrm{Cr}, \mathrm{Mo}, \mathrm{W}$ ) colusites, Angew. Chemie Int. Ed. 58 (2019) 15455-15463. https://doi.org/10.1002/anie.201908579.

[21] Y. Kikuchi, Y. Bouyrie, M. Ohta, K. Suekuni, M. Aihara, T. Takabatake, Vanadiumfree colusites $\mathrm{Cu}_{26} \mathrm{~A}_{2} \mathrm{Sn}_{6} \mathrm{~S}_{32}(\mathrm{~A}=\mathrm{Nb}$, Ta) for environmentally friendly thermoelectrics, J. Mater. Chem. A. 4 (2016) 15207-15214. https://doi.org/10.1039/C6TA05945G.

[22] F.S. Kim, K. Suekuni, H. Nishiate, M. Ohta, H.I. Tanaka, T. Takabatake, Tuning the charge carrier density in the thermoelectric colusite, J. Appl. Phys. 119 (2016) 175105. https://doi.org/10.1063/1.4948475.

[23] Y. Bouyrie, M. Ohta, K. Suekuni, Y. Kikuchi, P. Jood, A. Yamamoto, T. Takabatake, Enhancement in the thermoelectric performance of colusites $\mathrm{Cu}_{26} \mathrm{~A}_{2} \mathrm{E}_{6} \mathrm{~S}_{32}(\mathrm{~A}=\mathrm{Nb}, \mathrm{Ta}$; $\mathrm{E}=\mathrm{Sn}, \mathrm{Ge})$ using E-site non-stoichiometry, J. Mater. Chem. C. 5 (2017) 4174-4184. https://doi.org/10.1039/C7TC00762K.

[24] K. Suekuni, Y. Shimizu, E. Nishibori, H. Kasai, H. Saito, D. Yoshimoto, K. Hashikuni, 
Y. Bouyrie, R. Chetty, M. Ohta, E. Guilmeau, T. Takabatake, K. Watanabe, M. Ohtaki, Atomic-Scale Phonon Scatterers in Thermoelectric Colusites with a Tetrahedral Framework Structure, J. Mater. Chem. A. 7 (2019) 228-235. https://doi.org/10.1039/C8TA08248K.

[25] Y. Shen, C. Li, R. Huang, R. Tian, Y. Ye, L. Pan, K. Koumoto, R. Zhang, C. Wan, Y. Wang, Eco-friendly p-type $\mathrm{Cu}_{2} \mathrm{SnS}_{3}$ thermoelectric material: crystal structure and transport properties, Sci. Rep. 6 (2016) 32501. https://doi.org/https://doi.org/10.1038/srep32501.

[26] M.L. Liu, F.Q. Huang, L.D. Chen, I.W. Chen, A wide-band-gap p-type thermoelectric material based on quaternary chalcogenides of $\mathrm{Cu}_{2} \mathrm{ZnSnQ}_{4}(\mathrm{Q}=\mathrm{S}, \mathrm{Se})$, Appl. Phys. Lett. 94 (2009) 202103. https://doi.org/https://doi.org/10.1063/1.3130718.

[27] H. Yang, L.A. Jauregui, G. Zhang, Y.P. Chen, Y. Wu, Nontoxic and abundant copper zinc tin sulfide nanocrystals for potential high-temperature thermoelectric energy harvesting, Nano Lett. 12 (2012) 540-545. https://doi.org/10.1021/n1201718z.

[28] C. Bourgès, P. Lemoine, O.I. Lebedev, R. Daou, V. Hardy, B. Malaman, E. Guilmeau, Low thermal conductivity in ternary $\mathrm{Cu}_{4} \mathrm{Sn}_{7} \mathrm{~S}_{16}$ compound, Acta Mater. 97 (2015) 180190. https://doi.org/https://doi.org/10.1016/j.actamat.2015.06.046.

[29] H. Xie, X. Su, S. Hao, C. Zhang, Z. Zhang, W. Liu, Y. Yan, C. Wolverton, X. Tang, M.G. Kanatzidis, Large thermal conductivity drops in the diamondoid lattice of $\mathrm{CuFeS}_{2}$ by discordant atom doping, J. Am. Chem. Soc. 141 (2019) 18900-18909. https://doi.org/10.1021/jacs.9b10983.

[30] X. Lu, D.T. Morelli, Y. Xia, F. Zhou, V. Ozolins, H. Chi, X. Zhou, C. Uher, High performance thermoelectricity in earth-abundant compounds based on natural mineral 
tetrahedrites, Adv. Energy Mater. 3 (2013) 342-348.

https://doi.org/10.1002/aenm.201200650.

[31] K. Suekuni, K. Tsuruta, T. Ariga, M. Koyano, Thermoelectric properties of mineral tetrahedrites $\mathrm{Cu}_{10} \operatorname{Tr}_{2} \mathrm{Sb}_{4} \mathrm{~S}_{13}$ with low thermal conductivity, Appl. Phys. Express. 5 (2012) 2-5. https://doi.org/10.1143/APEX.5.051201.

[32] K. Suekuni, K. Tsuruta, M. Kunii, H. Nishiate, E. Nishibori, S. Maki, M. Ohta, A. Yamamoto, M. Koyano, High-performance thermoelectric mineral $\mathrm{Cu}_{12-\mathrm{x}} \mathrm{Ni}_{\mathrm{x}} \mathrm{Sb}_{4} \mathrm{~S}_{13}$ tetrahedrite, J. Appl. Phys. 113 (2013) 043712. https://doi.org/10.1063/1.4789389.

[33] Y. Bouyrie, C. Candolfi, V. Ohorodniichuk, B. Malaman, A. Dauscher, J. Tobola, B. Lenoir, Crystal structure, electronic band structure and high-temperature thermoelectric properties of Te-substituted tetrahedrites $\mathrm{Cu}_{12} \mathrm{Sb}_{4-\mathrm{x}} \mathrm{Te}_{\mathrm{x}} \mathrm{S}_{13}(0.5 \leq \mathrm{x} \leq 2.0)$, J. Mater. Chem. C. 3 (2015) 10476-10487. https://doi.org/10.1039/c5tc01636c.

[34] R. Chetty, A. Bali, R.C. Mallik, Tetrahedrites as thermoelectric materials: An overview, J. Mater. Chem. C. 3 (2015) 12364-12378. https://doi.org/10.1039/c5tc02537k.

[35] T. Barbier, P. Lemoine, S. Gascoin, O.I. Lebedev, A. Kaltzoglou, P. Vaqueiro, A. V. Powell, R.I. Smith, E. Guilmeau, Structural stability of the synthetic thermoelectric ternary and nickel-substituted tetrahedrite phases, J. Alloys Compd. 634 (2015) 253262. https://doi.org/10.1016/j.jallcom.2015.02.045.

[36] T. Barbier, S. Rollin-Martinet, P. Lemoine, F. Gascoin, A. Kaltzoglou, P. Vaqueiro, A. V. Powell, E. Guilmeau, Thermoelectric Materials: A New Rapid Synthesis Process for Nontoxic and High-Performance Tetrahedrite Compounds, J. Am. Ceram. Soc. 99 (2016) 51-56. https://doi.org/10.1111/jace.13838. 
[37] T. Barbier, P. Lemoine, S. Martinet, M. Eriksson, M. Gilmas, E. Hug, G. Guélou, P. Vaqueiro, A.V. Powell, E. Guilmeau, Up-scaled synthesis process of sulphur-based thermoelectric materials, RSC Adv. 6 (2016) 10044-10053. https://doi.org/10.1039/c5ra23218j.

[38] X. Du, F. Cai, X. Wang, Enhanced thermoelectric performance of chloride doped bismuth sulfide prepared by mechanical alloying and spark plasma sintering, J. Alloys Compd. 587 (2014) 6-9. https://doi.org/https://doi.org/10.1016/j.jallcom.2013.10.185.

[39] Q. Tan, W. Sun, Z. Li, J.-F. Li, Enhanced thermoelectric properties of earth-abundant $\mathrm{Cu}_{2} \mathrm{SnS}_{3}$ via In doping effect, J. Alloys Compd. 672 (2016) 558-563. https://doi.org/https://doi.org/10.1016/j.jallcom.2016.02.185.

[40] P. Baláž, M. Hegedüs, M. Reece, R.-Z. Zhang, T. Su, I. Škorvánek, J. Briančin, M. Baláž, M. Mihálik, M. Tešínsky, M. Achimovičová, Mechanochemistry for Thermoelectrics: Nanobulk $\mathrm{Cu}_{6} \mathrm{Fe}_{2} \mathrm{SnS}_{8} / \mathrm{Cu}_{2} \mathrm{FeSnS}_{4}$ Composite Synthesized in an Industrial Mill, J. Electron. Mater. 48 (2019) 1846-1856. https://doi.org/10.1007/s11664-019-06972-7.

[41] A. Ostovari Moghaddam, A. Shokuhfar, A. Cabot, A. Zolriasatein, Synthesis of bornite $\mathrm{Cu}_{5} \mathrm{FeS}_{4}$ nanoparticles via high energy ball milling: Photocatalytic and thermoelectric properties, Powder Technol. 333 (2018) 160-166. https://doi.org/https://doi.org/10.1016/j.powtec.2018.04.023.

[42] S.O.J. Long, A. V Powell, P. Vaqueiro, S. Hull, High Thermoelectric Performance of Bornite through Control of the $\mathrm{Cu}(\mathrm{II})$ Content and Vacancy Concentration, Chem. Mater. 30 (2018) 456-464. https://doi.org/10.1021/acs.chemmater.7b04436.

[43] X. Lu, D.T. Morelli, Rapid synthesis of high-performance thermoelectric materials 
directly from natural mineral tetrahedrite, MRS Commun. 3 (2013) 129-133. https://doi.org/10.1557/mrc.2013.26.

[44] H.-S.S. Kim, Z.M. Gibbs, Y. Tang, H. Wang, G.J. Snyder, Characterization of Lorenz number with Seebeck coefficient measurement, APL Mater. 3 (2015) 41506. https://doi.org/10.1063/1.4908244.

[45] E. Alleno, D. Bérardan, C. Byl, C. Candolfi, R. Daou, R. Decourt, E. Guilmeau, S. Hébert, J. Hejtmanek, B. Lenoir, P. Masschelein, V. Ohorodnichuk, M. Pollet, S. Populoh, D. Ravot, O. Rouleau, M. Soulier, Invited Article: A round robin test of the uncertainty on the measurement of the thermoelectric dimensionless figure of merit of $\mathrm{Co}_{0.97} \mathrm{Ni}_{0.03} \mathrm{Sb}_{3}$, Rev. Sci. Instrum. 86 (2015) 11301. https://doi.org/10.1063/1.4905250.

[46] A.C. Larson, R.B. Von Dreele, General Structure Analysis System (GSAS), Los Alamos Natl. Lab. Rep. LAUR 86-748. (1994).

[47] B. Toby, EXPGUI, a graphical user interface for GSAS, J. Appl. Crystallogr. 34 (2001) 210-213. https://doi.org/10.1107/S0021889801002242.

[48] P. Lemoine, V. Pavan Kumar, G. Guélou, V. Nassif, B. Raveau, E. Guilmeau, Thermal Stability of the Crystal Structure and Electronic Properties of the High Power Factor Thermoelectric Colusite $\mathrm{Cu}_{26} \mathrm{Cr}_{2} \mathrm{Ge}_{6} \mathrm{~S}_{32}$, Chem. Mater. 32 (2020) 830-840. https://doi.org/10.1021/acs.chemmater.9b04378.

[49] P. Lemoine, C. Bourgès, T. Barbier, V. Nassif, S. Cordier, E. Guilmeau, High temperature neutron powder diffraction study of the $\mathrm{Cu}_{12} \mathrm{Sb}_{4} \mathrm{~S}_{13}$ and $\mathrm{Cu}_{4} \mathrm{Sn}_{7} \mathrm{~S}_{16}$ phases, J. Solid State Chem. 247 (2017) 83-89. https://doi.org/https://doi.org/10.1016/j.jssc.2017.01.003.

[50] G.J. Snyder, S. Toberer, Complex thermoelectric materials, Nat. Mater. 7 (2008) 105- 
114. https://doi.org/10.1038/nmat2090.

[51] M. Cutler, J.F. Leavy, R.L. Fitzpatrick, Electronic Transport in Semimetallic Cerium Sulfide, Phys. Rev. 133 (1964) A1143-A1152.

https://doi.org/10.1103/PhysRev.133.A1143.

[52] M. Beaumale, T. Barbier, Y. Bréard, G. Guélou, A.V. Powell, P. Vaqueiro, E. Guilmeau, Electron doping and phonon scattering in $\mathrm{Ti}_{1+x} \mathrm{~S}_{2}$ thermoelectric compounds, Acta Materialia 78 (2014) 86. https://doi.org/ 10.1016/j.actamat.2014.06.032.

[53] Y. Chen, D. Wang, Y. Zhou, Q. Pang, J. Shao, G. Wang, J. Wang, L.D. Zhao, Enhancing the thermoelectric performance of $\mathrm{Bi}_{2} \mathrm{~S}_{3}$ : A promising earth-abundant thermoelectric material, Front. Phys. 14 (2019) 14-16. https://doi.org/10.1007/s11467018-0845-4.

[54] J.-B. Labégorre, A. Virfeu, A. Bourhim, H. Willeman, T. Barbier, F. Appert, J. Juraszek, B. Malaman, A. Huguenot, R. Gautier, V. Nassif, P. Lemoine, C. Prestipino, E. Elkaim, L. Pautrot-d'Alençon, T. Le Mercier, A. Maignan, R. Al Rahal Al Orabi, E. Guilmeau, $\mathrm{XBi}_{4} \mathrm{~S}_{7}(\mathrm{X}=\mathrm{Mn}, \mathrm{Fe})$ : New Cost-Efficient Layered n-Type Thermoelectric Sulfides with Ultralow Thermal Conductivity, Adv. Funct. Mater. 9 (2019) 1904112. https://doi.org/10.1002/adfm.201904112.

[55] Y.M. Han, J. Zhao, M. Zhou, X.X. Jiang, H.Q. Leng, L.F. Li, Thermoelectric performance of SnS and SnS-SnSe solid solution, J. Mater. Chem. A. 3 (2015) 45554559. https://doi.org/10.1039/c4ta06955b.

[56] L.D. Zhao, S.H. Lo, J. He, H. Li, K. Biswas, J. Androulakis, C.I. Wu, T.P. Hogan, D.Y. Chung, V.P. Dravid, M.G. Kanatzidis, High performance thermoelectrics from earth- 
abundant materials: Enhanced figure of merit in $\mathrm{PbS}$ by second phase nanostructures, $\mathrm{J}$. Am. Chem. Soc. 133 (2011) 20476-20487. https://doi.org/10.1021/ja208658w.

[57] L.D. Zhao, J. He, S. Hao, C.I. Wu, T.P. Hogan, C. Wolverton, V.P. Dravid, M.G. Kanatzidis, Raising the thermoelectric performance of p-type Pbs with endotaxial nanostructuring and valence-band offset engineering using $\mathrm{CdS}$ and $\mathrm{ZnS}$, J. Am. Chem. Soc. 134 (2012) 16327-16336. https://doi.org/10.1021/ja306527n.

[58] G. Tan, S. Hao, J. Zhao, C. Wolverton, M.G. Kanatzidis, High Thermoelectric Performance in Electron-Doped $\mathrm{AgBi}_{3} \mathrm{~S}_{5}$ with Ultralow Thermal Conductivity, J. Am. Chem. Soc. 139 (2017) 6467-6473. https://doi.org/10.1021/jacs.7b02399.

[59] B. Du, R. Zhang, M. Liu, K. Chen, H. Zhang, M.J. Reece, Crystal structure and improved thermoelectric performance of iron stabilized cubic $\mathrm{Cu}_{3} \mathrm{SbS}_{3}$ compound, J. Mater. Chem. C. 7 (2019) 394-404. https://doi.org/10.1039/c8tc05301d.

[60] P. Mangelis, P. Vaqueiro, A. V. Powell, Improved Thermoelectric Performance through Double Substitution in Shandite-Type Mixed-Metal Sulfides, ACS Appl. Energy Mater. 3 (2020) 2168-2174. https://doi.org/10.1021/acsaem.9b02272.

[61] X. Shen, Y. Xia, C.C. Yang, Z. Zhang, S. Li, Y.H. Tung, A. Benton, X. Zhang, X. Lu, G. Wang, J. He, X. Zhou, High Thermoelectric Performance in Sulfide-Type Argyrodites Compound $\mathrm{Ag}_{8} \mathrm{Sn}\left(\mathrm{S}_{1-\mathrm{x}} \mathrm{Se}_{\mathrm{x}}\right)_{6}$ Enabled by Ultralow Lattice Thermal Conductivity and Extended Cubic Phase Regime, Adv. Funct. Mater. 2000526 (2020) 1-10. https://doi.org/10.1002/adfm.202000526.

[62] T. Tanimoto, K. Suekuni, T. Tanishita, H. Usui, T. Tadano, T. Kamei, H. Saito, H. Nishiate, C.H. Lee, K. Kuroki, M. Ohtaki, Enargite $\mathrm{Cu}_{3} \mathrm{PS}_{4}$ : A Cu-S-Based Thermoelectric Material with a Wurtzite-Derivative Structure, Adv. Funct. Mater. 
(2020) 2000973. https://doi.org/10.1002/adfm.202000973.

[63] M. Ohta, H. Obara, A. Yamamoto, Preparation and Thermoelectric Properties of Chevrel-Phase $\mathrm{Cu}_{x} \mathrm{Mo}_{6} \mathrm{~S}_{8}(2.0 \leq \mathrm{x} \leq 4.0)$, Mater. Trans. 50 (2009) 2129-2133. https://doi.org/10.2320/matertrans.MAW200918. 